\title{
Optimal Resonance-Free Third-Order High-Pass Filters Based on Minimization of the Total Cost of the Filters
}

\section{Using Crow Search Algorithm}

Shady H. E. Abdel Aleem ${ }^{\mathrm{a} *}$, Ahmed F. Zobaa ${ }^{\mathrm{b}}$, and Murat E. Balci ${ }^{\mathrm{c}}$

${ }^{a} 15^{\text {th }}$ of May Higher Institute of Engineering, Mathematical and Physical Sciences, Helwan, Cairo, Egypt (email: engyshady@ieee.org)

${ }^{b}$ College of Engineering, Design \& Physical Sciences, Brunel University London, Uxbridge United Kingdom (email: azobaa@ieee.org)

${ }^{c}$ Electrical and Electronics Engineering, Balikesir University, Balikesir, Turkey (email: mbalci@balikesir.edu.tr)

*Corresponding author: T: +201227567489 | E-mail address: engyshady@ieee.org 
Abstract-The most common damped filters (DFs) are the second-order, third-order, $C$-type, and double-tuned filters. Other DFs such as the first-order and band-pass filters exist, but their high operating losses considerably diminish their usage. In this paper, firstly, for the third-order damped filter with equal and unequal capacitors, the relations among their circuit parameters are derived. Secondly, the optimal design problem of the two third-order high-pass filters is formulated by regarding these expressions to minimize the filter cost taking into account both the investment and operating expenses. The total and individual harmonic distortion indices, power factor and the harmonic voltage amplification ratios which measure the filter's resonance damping capability, are considered as constraints. A recent metaheuristic optimization technique based on the intelligent behavior of crows, known as the Crow Search Algorithm (CSA), is employed for the solution of the formulated design problem. Further, a comparative analysis of the two designs of the third-order highpass filters and a third-order $C$-type filter is presented. The results reveal that all the proposed filters guarantee no electrical resonance hazards while maintaining the allowable limits for the various performance indices of the system, load, and filter. Besides, the comparative analysis validates that the $C$-type filter provides higher power factor, system efficiency and transmission loss improvement than the other two filters, and that the proposed filters achieve almost the same voltage and current harmonic mitigation levels. The solution of the cost minimization problem reveals that the $C$-type filter and the third-order high-pass filter with equal capacitors have the worst and best resonance damping capabilities respectively, under the worst case conditions. Additionally, the filters with the lowest and highest cost are found as the third-order filter with unequal capacitors and the $C$-type one, respectively. Besides, the CSA is compared to the genetic algorithm (GA), and particle swarm optimization (PSO) techniques and the results show the fast convergence capability and the effectiveness of the proposed algorithm in solving the problem of optimal design of third-order resonance-free passive filters in distribution networks.

Keywords - Damped filters; harmonic distortion; harmonics mitigation; metaheuristic algorithms; optimization; power factor correction; resonance. 


\section{Nomenclature}

\begin{tabular}{|c|c|}
\hline$A P$ & Awareness probability \\
\hline$D P F$ & Displacement power factor \\
\hline$E_{S n}$ & The harmonic system background voltage at harmonic order $n$ \\
\hline$F C$ & Total cost of the filter \\
\hline$f l$ & Flight length \\
\hline$F_{P L}$ & Power losses associated with the filter \\
\hline$F S$ & Impedance-frequency response index \\
\hline$F_{V}$ & Filter utilization percentage \\
\hline$h$ & Tuning order of the filter \\
\hline$H D I_{n}$ & Individual harmonic distortion of the line current at harmonic order $n$ in percent \\
\hline$H D I_{s t d}$ & The IEEE standard 519's limit of the $n$th $H D I_{n}$ in percent \\
\hline$H D V$ & Individual harmonic distortion of the load voltage in percent \\
\hline$H D V_{s t d}$ & The IEEE standard 519's limit of the $H D V$ in percent \\
\hline$H M C$ & Harmonic mitigation capability of the filters in percent \\
\hline$H V A R$ & Harmonic voltage amplification ratio \\
\hline$H V A R_{r e f}$ & Reference (limit) value of $H V A R$ \\
\hline$H V A R_{\text {worst }}$ & $H V A R$ value for the worst case scenario \\
\hline$i$ & Interest rate \\
\hline$I_{C}$ & Rms current of the main capacitor $\left(C_{1}\right)$ of the filters \\
\hline$I C$ & Investment cost of the filter \\
\hline$I_{N L}(\omega)$ & Harmonic nonlinear load current at the angular frequency $(\omega)$ \\
\hline$I_{\text {rated }}$ & Rated current of the main capacitor $\left(C_{1}\right)$ of the filters \\
\hline$I_{S n}$ & The $n$th harmonic line current \\
\hline$k$ & Lifetime of filter in years \\
\hline$O C$ & Operating cost of the filters \\
\hline$n$ & Harmonic number \\
\hline$P F$ & Power factor in percent \\
\hline$P_{V}$ & Present value \\
\hline$Q_{C 1}, Q_{C 2}$ & Volt-ampere rating of the main capacitor $\left(C_{1}\right)$ and auxiliary capacitor $\left(C_{2}\right)$ of the filters \\
\hline$Q_{\text {rated }}$ & Rated reactive power of the main capacitor $\left(C_{1}\right)$ of the filter \\
\hline$Q_{x}$ & Volt-ampere rating of the inductor $(\mathrm{L})$ of the filters \\
\hline$R_{F}(\omega)$ & The filter equivalent resistance at the angular frequency $(\omega)$ \\
\hline$R_{F n}$ & The $n$th harmonic resistance of the $n$th harmonic filter impedance $Z_{F n}$ \\
\hline $\mathrm{R}_{S n}$ & The $n$th harmonic resistance of the $n$th harmonic Thevenin equivalent impedance $Z_{S n}$ \\
\hline$t$ & Iteration number \\
\hline$t_{\max }$ & Maximum number of iterations \\
\hline$T H D I$ & Total harmonic distortion of the line current in percent \\
\hline$T H D V$ & Total harmonic distortion of the load voltage in percent \\
\hline$T P_{L}$ & Transmission power loss \\
\hline$U_{C}, U_{X}$ & Unit costs of the capacitors and inductors of the filters, respectively \\
\hline$U_{V}$ & Consumption charge rate \\
\hline$V$ & Nominal voltage of the system \\
\hline$V_{C}$ & Rms voltage of the main capacitor $\left(\mathrm{C}_{1}\right)$ of the filters \\
\hline$V_{L n}$ & The $n$th harmonic load voltage \\
\hline
\end{tabular}




$\begin{array}{ll}V_{\text {peak }} & \text { Peak voltage of the main capacitor }\left(\mathrm{C}_{1}\right) \text { of the filters } \\ V_{\text {rated }} & \text { Rated voltage of the main capacitor }\left(\mathrm{C}_{1}\right) \text { of the filters } \\ X_{F}(\omega) & \text { The filter equivalent reactance at the angular frequency }(\omega) \\ X_{F n} & \text { The } n \text {th harmonic reactance of the } n \text {th harmonic filter impedance } Z_{F n} \\ X_{S n} & \text { The } n \text {th harmonic reactance of the } n \text {th harmonic Thevenin equivalent impedance } Z_{S n} \\ Z_{F}(\omega) & \text { The filter equivalent impedance at the angular frequency }(\omega) \\ Z_{L}(\omega) & \text { The linear load impedance at the angular frequency }(\omega) \\ Z_{F L}(\omega) & \text { The parallel equivalent impedance of } Z_{F}(\omega) \text { and } Z_{L}(\omega) \text { at the angular frequency }(\omega) \\ Z_{n} & \text { The } n \text {th harmonic equivalent impedance seen from the harmonic current source side } \\ Z_{S}(\omega) & \text { The system Thevenin equivalent impedance at the angular frequency }(\omega) \\ \alpha, \beta, \gamma & \text { Collective variables used for expressing } R_{F}(\omega) \text { and } X_{F}(\omega) \\ \eta_{T} & \text { Transmission efficiency in percent } \\ \varphi_{n} & \text { The harmonic phase difference between the } n \text {th harmonic line current and load voltage } \\ \omega_{h} & \text { Angular frequency at the tuning harmonic order }(\mathrm{h}) \text { of the filter }\end{array}$

\section{List of abbreviations}

$\begin{array}{ll}\text { CSA } & \text { Crow search algorithm } \\ \text { DF } & \text { Damped filter } \\ \text { GA } & \text { Genetic algorithm } \\ \text { OF } & \text { Objective function } \\ \text { PSO } & \text { Particle swarm optimization }\end{array}$




\section{Introduction}

Harmonic distortion is one of the main power quality problems for power systems, particularly with the advance of power electronic equipment and nonlinear loads that worsen the quality of power. Recently, other developments in power systems have led to new challenges in the quality of the power domain, such as integration of large-scale renewable energy based generation technologies, and the expansion of interconnected power grids [1-6].

Among the numerous solutions and power conditioning devices that improve the quality of power and mitigate harmonics; passive filtering is still widely used for voltage support, reactive power compensation, and harmonic mitigation in transmission and distribution systems due to simplicity, low cost, easy surveillance and maintenance, and high reliability [7]. On the other hand, tuned passive filters suffer from various drawbacks such as parameter variations that may occur due to frequency deviation, manufacture tolerance, and temperature change. Besides, the filtering performance is affected by the source resistance which may vary and hence leads to resonance occurrence between the filter and system [3,8-10].

Passive filters were firstly installed in the 1940s [9]. In its broadest scene, they are classified based on the method of connection into the series and shunt filters. Series filters present a highimpedance series path to block harmonics at the tuning frequency, while shunt filters present a lowimpedance shunt path to divert harmonics at the tuning frequency. Shunt filters are still more employed for harmonics mitigation than the series filters because of the significant fundamental power loss and voltage drop of series filters, as well as their high fundamental voltage-ampere (VA) rating. Moreover, shunt filters are capable of supporting voltage and compensating reactive power at the fundamental frequency $[3,11,12]$.

According to the nonlinear loads being considered, series filters are more suitable for voltagesource nonlinear loads or AC drives [13], while shunt filters are more suitable for current-source nonlinear loads or DC drives [14].

Further, shunt filters are classified based on their function, into tuned and damped filters. Tuned filters are filters that are adjusted to mitigate harmonics by providing a low impedance path at one, two, or even three tuning harmonic frequencies, known as single-tuned, double-tuned, and triple-tuned (less common) filters, respectively. Single-tuned filters are common in distribution systems and industrial applications, while the double-tuned and the triple-tuned filters are common in high-voltage applications and high-voltage direct current (HVDC) transmission systems [3,11]. On the other hand, damped filters such as the first-order, second-order, third-order, $C$-type, damped double-tuned, and bandpass filters, are high-pass filters (HPFs) that provide a low impedance path to a broad range of harmonics [3,15]. They are widely used in transmission systems, HVDC links, and recently in 
distribution and industrial systems [16,17]. Compared to the tuned filters, they are less sensitive to variations that may occur due to frequency deviation, manufacture tolerance, and temperature change. Also, they can dampen the harmonic amplification which may occur by the resonance between the filter and the system. On the other hand, assuming the same fundamental VA rating, damped filters provide worse harmonic filtering compared to the tuned filters as the minimum impedance provided by a damped filter cannot achieve a value comparable to that of the tuned filter at the tuned frequency [11].

Although the third-order filter passive filter has been in operation for years, its design algorithm still poses a difficulty. In the literature, two design concepts of the third-order DFs exist. Ref. [18] used equal capacitance condition to size the filter' capacitors, while [19] gave preponderance for the unequal capacitors, but without presenting a convenient algorithm to find the different capacitor values.

Ref. [20] presented possible relations between the two capacitors and indicated that careful selection of the ratio between them should be investigated while taking into account the filter power loss, and the resonance conditions. Despite the recommendation of using different capacitors in that study, the ratio between them is assumed a case dependent, and no decision has been reached.

Recently, [21] presented a mathematical design for the filter based on minimization of the filter power loss at the fundamental frequency, and then it was used in [16] to size the filters as resonancefree filters based on the presented mathematical expressions. Still, the mathematical formulations do not differentiate between the two designs of the third-order filters and do not guarantee that the voltage and current harmonic distortion levels will comply with their standard limits stated in IEEE 519. Consequently, the features, merits, and demerits of each filter design should be investigated under different design goals and conditions.

This paper presents a detailed mathematical approach of resonance-free third-order HPF design, and hence presents its optimal design, while taking into account various design scenarios. The objective function is the total filter cost. The investment cost takes into account the filter size, while the operating cost takes into account the energy loss cost. Economic indices represented by investment and operating costs, and technical power quality indices such as voltage total and individual harmonic distortions, current total and individual harmonic distortions, transmission loss and efficiency, power factor, loading limits of the capacitors, and harmonic mitigation and resonance damping capabilities, are taken into consideration. Furthermore, comparative analysis of the two design scenarios of the third-order HPF and the third-order $C$-type filters are presented in details to evaluate the performance of third-order damped filters. Besides, as not all harmonic mitigation approaches are designed to operate well with background voltage distortion; background voltage distortion is considered to show the worst-case scenario of voltage source nonlinearity and its impact on the performance of the filters.

Crow Search Algorithm (CSA) is used for the optimal filter design to minimize the total filter cost that includes both the investment and operating expenses. CSA is a nature-inspired and population- 
based metaheuristic algorithm that has recently been developed to solve single unconstrained and constrained optimization problems [22]. It is based on the intelligent behavior of crows in storing their extra food (surplus), preventing the food place from being seen or discovered by others, and bringing their food back when they need. It has fewer parameters, which should be set, faster convergence capability and higher sensitivity when compared to the widely known metaheuristic optimization algorithms. Due to these advantages, it has been recently employed to solve many engineering problems in the literature [22-26]. Accordingly, in this paper, CSA is suggested for the solution of the optimal passive harmonic filter design problem.

The results show that the proposed filter designs guarantee no resonance at characteristic or noncharacteristic harmonics of the DC drive loads, while maintaining the allowable limits for the considered performance indices of the system, loads, and filters.

Besides, the CSA is compared to the genetic algorithm (GA), and particle swarm optimization (PSO) techniques and the simulation results show the fast convergence capability and effectiveness of the proposed algorithm in solving the problem of optimal design of third-order resonance-free passive filters in distribution networks.

\section{- Contributions to knowledge}

The contribution of this work is threefold; the first is a comparative evaluation of the different designs of the resonance-free third-order HPF filters to show the advantages and disadvantages of each scheme under different design conditions. The comparative evaluation is detailed by regarding economic indices such as investment and operating costs, and industrial power quality indices as total and individual harmonic distortions of voltage and current, harmonic mitigation and resonance damping capabilities, transmission loss, power factor and loading limits of the capacitors. The second contribution of the paper is that an optimal design algorithm is firstly developed to design resonancefree third-order high-pass filters. The third contribution of the paper is that it presents a successful implementation of a recent metaheuristic optimization algorithm, CSA, for the design of passive harmonic filters. It is seen from the analysis that CSA provides much more sensitive results when compared to two widely implemented optimal passive filter design method as PSO and GA.

\section{Third-order high-pass damped filters}

Fig. 1 shows the four common types of the damped filters [11]. The $1^{\text {st }}$ order HPF shown in Fig. 1(a) is the simplest one as it consists of a capacitor $C_{1}$ that provides capacitive reactance for displacement power factor (DPF) correction and is connected in series with a resistor $R$ that provides the damping characteristic.

Fig. 1(b) shows the configuration of the $2^{\text {nd }}$ order HPF which consists of an inductor $L$ in parallel with a resistor $R$, and the resulted combination is in series with the primary capacitor $C_{1}$. Although this 
filter provides better harmonic filtering performance and exhibits lower fundamental power loss than the $1^{\text {st }}$ order HPF, its power loss is high. Practically, this filter is employed in transmission systems in a composite filtering scheme [3]. Further, to achieve better harmonic filtering performance in a similar manner to the tuned filters with further reduction of the fundamental power losses; the configuration of the $2^{\text {nd }}$ order HPF is enhanced by adding an auxiliary capacitor $C_{2}$. As a result, two different third-order configurations are formed.

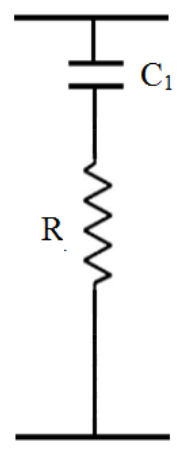

(a)

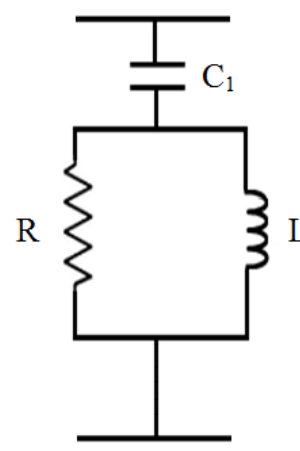

(b)

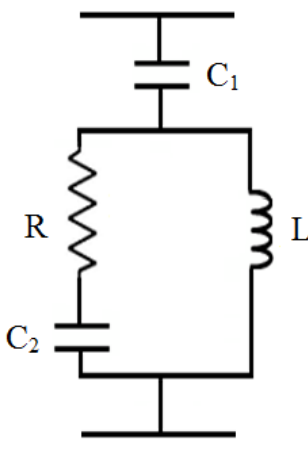

(c)

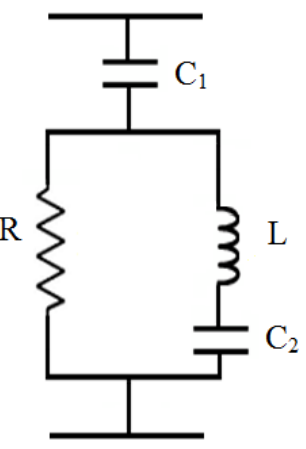

(d)

Fig. 1. The common types of high-pass damped filters, (a) $1^{\text {st }}$ order HPF, (b) $2^{\text {nd }}$ order HPF, (c) $3^{\text {rd }}$ order HPF, and (d) $C$-type filters.

Fig. 1(c) shows the first configuration of third-order HPFs, where $C_{2}$ is connected in series with the damping resistor $R$. The idea behind this enhancement is to significantly increase the impedance of the $\left(\mathrm{RC}_{2}\right)$ branch at the fundamental frequency compared to the inductive impedance provided by $L$. This arrangement will make the filter operate as a single-tuned filter at low frequencies below the tuning one; hence reduce the fundamental loss. At high frequencies, above the tuning frequency, the impedance of the $\left(\mathrm{RC}_{2}\right)$ branch becomes considerably lower than that provided by $L$; therefore, the filter will operate in a similar manner to the $1^{\text {st }}$ order HPFs [16].

Fig. 1(d) shows the second configuration of third-order HPFs, known as the $C$-type HPF, where $C_{2}$ is connected in series with $L$. In this configuration, $L$ and $C_{2}$ will resonate at the fundamental frequency. Hence, $R$ will be bypassed, and only $C_{1}$ will exist. This will lead to a little (practically) to no (theoretically) fundamental loss. Below the tuning frequency, the $C$-filter possesses a similar characteristic to the $2^{\text {nd }}$ order filters because of the small $C_{2}$ and large $L$ [27,28]. At high frequencies, above the tuning frequency, the impedance provided by the $\left(\mathrm{LC}_{2}\right)$ branch becomes considerably greater than $R$; hence, the filter will operate in a similar manner to the $1^{\text {st }}$ order HPFs $[16,17]$.

The harmonic equivalent impedance $Z_{F}(\omega)$ of the $3^{\text {rd }}$ order HPF shown in Fig. 1(c) is given in Eq. (1) as a function of the harmonic angular frequency $\omega$, where $R_{F}(\omega)$ is the filter equivalent harmonic resistance and $X_{F}(\omega)$ is the filter equivalent harmonic reactance.

$Z_{F}(\omega)=R_{F}(\omega)+j X_{F}(\omega)$

where, 
$R_{F}(\omega)=\frac{\alpha \omega^{4}}{\omega^{2}\left(R C_{2}\right)^{2}+\left(\omega^{2} L C_{2}-1\right)^{2}}$

$X_{F}(\omega)=\frac{N_{X}(\omega)}{D_{X}(\omega)}=\frac{\beta \omega^{4}+\gamma \omega^{2}-1}{\omega C_{1}\left(\omega^{2}\left(R C_{2}\right)^{2}+\left(\omega^{2} L C_{2}-1\right)^{2}\right)}$

where $N_{X}(\omega)$ and $D_{X}(\omega)$ are the numerator and denominator of $X_{F}(\omega)$, respectively. So that:

$\alpha=R L^{2} C_{2}^{2}$,

$\beta=R^{2} C_{2}^{2} L C_{1}-L^{2} C_{1} C_{2}-L^{2} C_{2}^{2}$, and

$\gamma=L C_{1}+2 L C_{2}-R^{2} C_{2}^{2}$.

Four design equations are required as the filter has four parameters. In the literature, two of them are widely known [21] which are based on the findings of the appropriate reactive power and the tuning frequency. In particular, the first equation is to determine the value of $C_{1}$ with regards to the nominal system voltage $(\mathrm{V})$, and the filter's nominal reactive power $\left(\mathrm{Q}_{\mathrm{F}}\right)$ which is required to improve the power factor (PF) and mitigate harmonics, as expressed in Eq. (5). The second equation is to determine the magnitude of the inductor $L$ with regards to the main capacitor $C_{1}$ and the harmonic order (h), in which $L$ resonates with $C_{1}$ at $h$, as given in Eq. (6). $\omega_{1}$ is the angular frequency at the fundamental harmonic while $\omega_{h}$ is the $h$ th angular frequency, where $\omega_{h}$ equals $h \omega_{1}$.

$$
\begin{aligned}
& X_{C 1}=\frac{V^{2}}{Q_{F}} \Rightarrow C_{1}=\frac{Q_{F}}{\omega_{1} V^{2}} \\
& X_{L}=\frac{X_{C 1}}{h^{2}} \Rightarrow L=\frac{1}{\omega_{h}^{2} C_{1}}
\end{aligned}
$$

The third equation is to determine the value of $C_{2}$ and to define its acceptable range. In view of that, one can consider that $X_{F}(\omega)$ greater than or equals zero at $\omega$ greater than or equals $\omega_{h}$. This means the filter reactance should be non-capacitive at the tuning frequency and above. Furthermore, this implies that the filter cannot resonate with the system impedance above its tuning frequency.

Recalling Eq. (3), one can see that $D_{X}(\omega)$ is always positive. Hence, the condition can be simplified to the $N_{X}(\omega)$ expression only, thus:

$$
N_{X}\left(\omega \geq \omega_{h}\right) \geq 0 \Rightarrow \beta \omega^{4}+\gamma \omega^{2}-1 \geq 0
$$

Substituting Eqs. (4) and (6) into Eq. (7); the following design constraint that presents the relationship between $C_{1}$ and $C_{2}$ is derived.

$N_{X}\left(\omega \geq \omega_{h}\right) \geq 0 \Rightarrow C_{1} \geq C_{2}$

Assuming $\omega^{2}=r$ and reformulating the $N_{X}(\omega)$ expression; the following quadratic polynomial will be formed, thus:

$$
N_{X}\left(\omega^{2}=r\right) \Rightarrow \beta r^{2}+\gamma r-1=\beta\left(r-r_{1}\right)\left(r+r_{2}\right)
$$


According to Vieta formulas under the condition that $\beta>0$, and considering the negative sign of the quadratic equation's constant; $r_{1}$ represents the negative root and $r_{2}$ represents the positive one (which is equal to $\omega_{h}^{2}$ ). Moreover, analysis of the polynomial coefficients showed that $N_{X}$ will be always positive at or above the tuning frequency if $\beta$ is greater than or equals zero. At $\beta=0$; substituting Eq. (6) into Eq. (4); one can get;

$$
R^{2} C_{2}^{2} L C_{1}-L^{2} C_{1} C_{2}-L^{2} C_{2}^{2}=0 \Rightarrow C_{2}=\frac{C_{1} L}{R^{2} C_{1}-L}
$$

When $C_{2}$ attains its maximum value, i.e. $C_{2}=C_{1}$; the minimum damping resistance equals $\left(2 L / C_{1}\right)^{0.5}$. Hence, for $\beta=0 ; N_{X}$ will equal $\gamma \omega^{2}-1$.

In brief, Eq. (7) will be greater than or equal zero under the below conditions.

$$
N_{X}\left(\omega \geq \omega_{h}\right) \geq 0 \Leftrightarrow \beta \geq 0 \Leftrightarrow\left\{\begin{array}{l}
C_{2} \geq \frac{C_{1} L}{R^{2} C_{1}-L} \\
R \geq \sqrt{\frac{2 L}{C_{1}}}
\end{array}\right.
$$

Equation (11) figures two conditions; the first one is the lowest boundary of $C_{2}$, and the second one is the range of the damping resistance $R$, its minimum value given as $\left(2 L / C_{1}\right)^{0.5}$, and the inverse relationship between $R$ and $C_{2}$ as the minimum value of $R$ occurs at the maximum value of $C_{2}$, at $C_{2}=C_{1}$. Hence, one can define the search region of $C_{2}$, as follows:

$$
\frac{C_{1} L}{R^{2} C_{1}-L} \leq C_{2} \leq C_{1}
$$

The impedance of the $\left(\mathrm{RC}_{2}\right)$ branch should be higher at the fundamental frequency compared to $L$ in order to reduce the current that will flow in it; hence reducing the associated fundamental power loss; this implies the use of the minimum possible value of $C_{2}$ to minimize the damping loss [29]. Due to this, [21] proposed the use of the expression of the minimum possible value of $C_{2}$ to maintain the lowest power loss at the fundamental frequency. On the other side, Eq. (8) shows that better harmonic filtering at the tuning frequency will be more likely to occur when $C_{1}$ equals $C_{2}$, as $X_{F}(\omega)$ equals zero. Due to this, some studies used the equal capacitance condition in the design of the $3^{\text {rd }}$ order filters [18].

The fourth design equation is to determine the value of the damping resistance $R$. It depends on finding the proper value of $R$ that provides the required damping characteristic or any other design objective, while maintaining the condition that $R$ should be equal or greater than $\left(2 L / C_{1}\right)^{0.5}$.

Finally, one should determine the required reactive power and tuning frequency based on the application case, and then calculates $C_{1}$ from Eq. (5), and $L$ from Eq. (6) to find initiative parameters of a third-order HPF. The minimum value of $R$ given in Eq. (11) that corresponds to the case of equal capacitors can be used a start. Consequently, if the initial design does not meet the design objective, the value of $R$ has to be increased while calculating the value of $C_{2}$ from Eq. (10) until the design objective 
is satisfied.

\section{Performance indices}

In this section, the system under study and the different power quality indices that will be used in assessing performance of the various designed filters, are presented.

\subsection{The system under study}

Fig. 2 shows the Thevenin equivalent circuit of a typical power system at the location of the nonlinear loads (variable frequency drives) and the $3^{\text {rd }}$ order HPF to be installed at the Point of Common Coupling (PCC), where $E_{S}(\omega)$ is the system background voltage, $Z_{S}(\omega)$ is the system equivalent Thevenin impedance which is calculated from the short-circuit level data, $Z_{L}(\omega)$ is the linear load impedance, and the harmonic current source $I_{N L}(\omega)$ represents the nonlinear load at the angular frequency $\omega$.

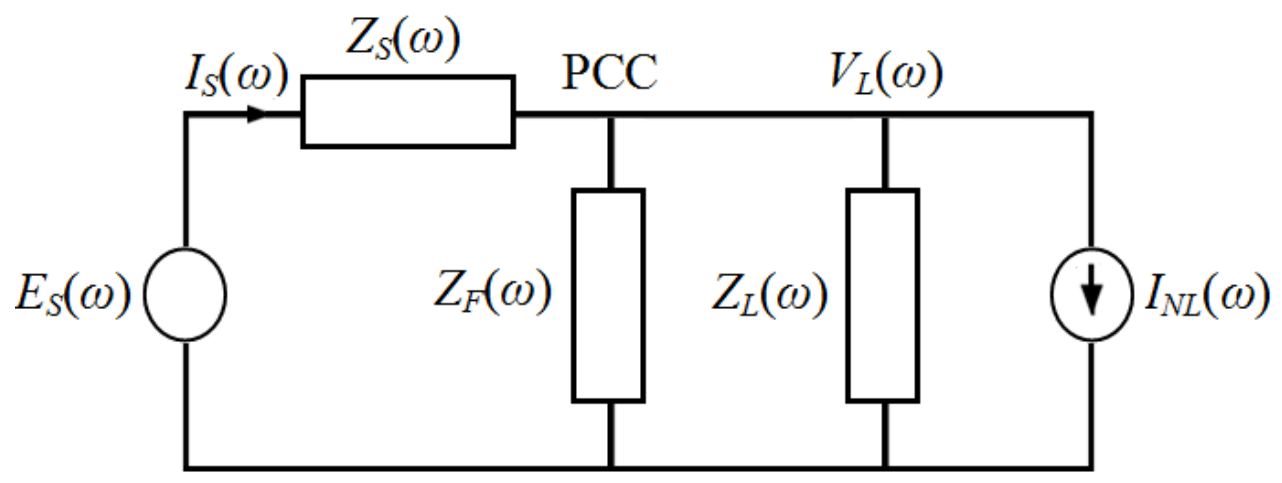

Fig. 2. The system under study

Expressions of the line current $I_{S}(\omega)$ and load voltage $V_{L}(\omega)$, calculated at the PCC, are given below, where $Z_{F L}(\omega)$ is the equivalent impedance of the parallel combination of $Z_{L}(\omega)$ and $Z_{F}(\omega)$.

$$
\begin{aligned}
& I_{S}(\omega)=\frac{E_{S}(\omega)}{Z_{S}(\omega)+Z_{F L}(\omega)}+\frac{Z_{F L}(\omega) I_{N L}(\omega)}{Z_{S}(\omega)+Z_{F L}(\omega)} \\
& V_{L}(\omega)=E_{S}(\omega)-\left(Z_{S}(\omega) I_{S}(\omega)\right)
\end{aligned}
$$

\subsection{Assessment indices of the system/load}

Various indices are used to assess the system/load performance with the installed filter such as the power factor $(\mathrm{PF})$, transmission power loss $\left(\mathrm{TP}_{\mathrm{L}}\right)$ and transmission efficiency $\left(\eta_{\mathrm{T}}\right)$, current total harmonic distortion (THDI) and voltage total harmonic distortion (THDV). They are given in Eqs. (15)-(18), respectively. 


$$
\begin{gathered}
P F=\frac{\sum_{n=1} V_{L n} I_{S n} \cos \left(\varphi_{n}\right)}{V_{L} I_{S}} \\
T P_{L}=\sum_{n=1} I_{S n}^{2} R_{S n}=\sum_{n=1} I_{S n}^{2}\left(R_{S 1} \sqrt{n}\right)
\end{gathered}
$$$$
\eta_{T}=\frac{\sum_{n=1} V_{L n} I_{S n} \cos \left(\varphi_{n}\right)}{\left(\sum_{n=1} V_{L n} I_{S n} \cos \left(\varphi_{n}\right)\right)+\left(\sum_{n=1} I_{S n}^{2} R_{S n}\right)}
$$

$T H D V=\frac{\sqrt{\sum_{n \geq 2} V_{L n}^{2}}}{V_{L 1}}, T H D I=\frac{\sqrt{\sum_{n \geq 2} I_{S n}^{2}}}{I_{S 1}}$

where, $V_{L n}$ and $I_{S n}$ are the rms values of the load voltage and line current at the harmonic number $n$, and $\varphi_{n}$ is the $n$th harmonic phase difference between them. $V_{L}$ and $I_{S}$ are the rms values of the PCC voltage and the line current, respectively. $R_{S n}$ and $X_{S n}$ are the $n$th harmonic resistive and inductive reactance components of the Thevenin equivalent impedance, respectively. Also, $R_{S 1}$ is the fundamental value of $R_{S n}$ that is considered frequency dependent as given in Eq. (16) to express the increase of the system equivalent resistance with the increase of the frequency.

\subsection{Performance and operational indices of the filters}

IEEE Standard 18-2012 [30] provides loading limits of shunt power capacitors operating in nonsinusoidal environment as expressed in Eqs. (19)-(22). Checking these limits after the selection of the appropriate voltage and kvar rating of the capacitors is necessary to protect the capacitors from damage, and to increase their lifetime [3].

$$
\begin{aligned}
& V_{C}=\sqrt{\left(\sum_{n=1}\left(\frac{V_{L n}}{Z_{F n}}\right) \frac{X_{C 1}}{n}\right)^{2}} \leq 1.1\left(V_{\text {rated }}\right) \\
& I_{C}=\sqrt{\left(\sum_{n=1} \frac{V_{L n}}{Z_{F n}}\right)^{2}} \leq 1.35\left(I_{\text {rated }}\right) \\
& V_{\text {peak }}=\sum_{n=1}\left(\frac{V_{L n}}{Z_{F n}}\right) \frac{X_{C 1}}{n} \leq 1.2\left(V_{\text {rated }}\right) \\
& Q_{C 1}=V_{C} I_{C} \leq 1.35\left(Q_{\text {rated }}\right)
\end{aligned}
$$

where $V_{C}, I_{C}$, and $Q_{C 1}$ are $C_{1}$ 's calculated rms voltage, current, and reactive power respectively, while $V_{\text {peak }}$ is its peak voltage. On the other side, $V_{\text {rated }}, I_{\text {rated }}$, and $Q_{\text {rated }}$ are the $C_{1}$ 's rated rms values of voltage, current, and reactive power respectively.

The total filter cost (FC) that includes both the investment (IC), and operating expenses (OC) will be used to assess the economic merits of the proposed filters. $F C$ is expressed as follows:

$$
F C=I C+O C=\left(U_{C}\left(Q_{C 1}+Q_{C 2}\right)+U_{X}\left(Q_{X}\right)\right)+O C
$$


where $Q_{C 1}, Q_{C 2}$, and $Q_{\mathrm{X}}$ are the volt-ampere ratings of the main and auxiliary capacitors, and the inductor, respectively. Also, $U_{C}$ and $U_{X}$ are the unit costs of the capacitor and inductor, respectively, so that $U_{C}=60$ L.E./kvar, and $U_{X}=75$ L.E./kvar.

Also, $O C$ represents the operating cost (cost of energy loss) which can be expressed as follows:

$$
O C=\left(1750 * P_{V} * F_{V} * U_{V}\right) F_{P L}
$$

where, $F_{V}$ is the filter utilization percentage which is assumed $100 \%, U_{V}$ is the consumption charge rate that is equal to 0.435 L.E. per kilowatt hour, and $F_{P L}$ is the filter-associated power loss. $P_{V}$ is the present value factor which is calculated based on the interest rate (i), which is assumed $5 \%$, and the filter lifetime $(\mathrm{k})$ which is considered 10 years based on a loading level of 1750 hours of work per year [31,32].

$$
\begin{aligned}
& P_{V}=\frac{(1+i)^{k}-1}{i(1+i)^{k}} \\
& F_{P L}=\sum_{n=1}\left(\frac{V_{L n}}{Z_{F n}}\right)^{2} \operatorname{Re}\left\{Z_{F n}\right\}
\end{aligned}
$$

The $n$th harmonic equivalent impedance $\left(Z_{n}\right)$ seen from the harmonic current source is expressed as given below:

$$
Z_{n}=\frac{Z_{S n} Z_{F n} Z_{L n}}{Z_{S n} Z_{F n}+Z_{S n} Z_{L n}+Z_{F n} Z_{L n}}
$$

The harmonic mitigation capability (HMC) is used to calculate the degree of reduction of the harmonic current fed back to the utility side in order to check the filter effectiveness in mitigating the customer side' harmonics. $H M C(\omega)$ is defined as the maximum fraction of the line current which can flow through the system equivalent Thevenin impedance due to the injected nonlinear load currents at $\omega$. It is expressed as follows [27]:

$$
H M C(\omega)=1-\left|\frac{Z_{n}(\omega)}{Z_{S}(\omega)}\right|
$$

\subsection{Capability of resonance damping}

\subsubsection{Normal operation resonance index}

As parallel resonance occurs, $\left|Z_{n}\right|$ will be amplified. The common solution is to derive the frequency at which maximum $Z_{n}$ occurs and shifting it below the lowest order harmonic frequency to avoid resonance. On the other hand, damping of parallel resonance means that $\left|Z_{n}\right|$ will get lower; therefore, the parallel resonance damping capability of the filter can be expressed using the impedancefrequency response index (FS) which is formulated by summing and grouping values of the $n$th harmonic equivalent impedance seen from the nonlinear load side, as follows [33,34]: 
$F S=\sum_{n=1}\left|\frac{Z_{n}}{n}\right|$

\subsubsection{Worst-case resonance index}

As resonance occurs, the ratio between the PCC voltages after and before installing a filter will be amplified. This ratio can be defined as a harmonic voltage amplification ratio (HVAR) and is given as follows [16]:

$$
\operatorname{HVAR}(\omega)=\frac{V_{L}(\omega)}{V_{L i}(\omega)}=\frac{Z_{F}(\omega)}{Z_{S}(\omega)+Z_{F}(\omega)}
$$

where $V_{L i}(\omega)$ represents the PCC voltage before connecting the filter to the PCC. Recalling [16], the worst harmonic voltage amplification ratio $\left(H V A R_{\text {worst }}\right)$ occurs when the system impedance is purely reactive, i.e., $R_{S}(\omega)=0$, and the system reactance is equal to the negative equivalent filter reactance, i.e., $\left(X_{S}(\omega)+X_{F}(\omega)=0\right)$. Hence, $\operatorname{HVAR}_{\text {worst }}(\omega)$ is a function of the filter parameters only as given in Eq. (31). This leads [16] to suggest that $\operatorname{HVAR}_{\text {worst }}(\omega)$ should be less than or equal to a reference (limit) value to act as a resonance-free filter.

The limit $\left(\mathrm{HVAR}_{\mathrm{ref}}\right)$ has no standard value yet. Arbitrarily, it may be set to 1.1 or 1.2 ; however, low ranges are preferable to guarantee the desired damping capability. The $H V A R_{\text {worst }}$ of a value close to one means that the PCC voltage after connecting the filter has almost the same value before connecting the filter, and this is considered the best scenario for a resonance-free DF.

$$
\operatorname{HVAR}_{\text {worst }}(\omega)=\sqrt{1+\left(\frac{X_{F}(\omega)}{R_{F}(\omega)}\right)^{2}} \leq H V A R_{\mathrm{ref}}(\omega)
$$

\section{Crow Search Algorithm (CSA)}

CSA was developed by 'Alireza Askarzadeh' in 2016 based on the intelligent behavior of crows [22]. Crows can recognize and memorize faces, use tools effectively, solve puzzles, communicate in sophisticated styles, and hide and retrieve their food. In a flock of crows, each one hides its excess food in a particular place and can find the location of the stored food after a long time. In the CSA, the flock, crows, and places are identified as population, searches, and position, respectively. Each position can be a feasible solution in the search space. The quality of the food is the objective (fitness) function, and the place of the best quality food is the global solution to the problem.

Crows are greedy creatures, and each crow wants to steal the food stored by other crows. This means that each member of the flock follows others for detecting their food positions and hiding its food well. CSA attempts to model this smart behavior of the crows to solve the engineering optimization problems as presented below.

For a folk with $N$ crows, the position of crow $i$ at iteration $t$ is specified as a vector, $x^{i, t}=$ 
$\left[x_{1}^{i, t}, x_{2}^{i, t}, \ldots, x_{d}^{i, t}\right]$ for $i=1,2, \ldots, N$ and $t=1,2, \ldots, t_{\max }$, where $d$ is the problem dimension (decision variables) and $t_{\max }$ is the maximum number of iterations. At iteration $t$, position of the hiding food that crow $i$ has memorized so far is given by $m^{i, t}$, so that $m^{i, t}=\left[m_{1}^{i, t}, m_{2}^{i, t}, \ldots, m_{d}^{i, t}\right]$.

The position of crow $i$ is updated based on the following procedure:

If crow $i$ attempts to follow crow $j$ to find the position of its hidden food place $m^{j, t}$, two states may occur:

State 1: if crow $j$ does not know that crow $i$ is following it; thus, crow $i$ will reach the $j$ th hiding place and the position of $i$ will be updated as follows:

$x^{i, t+1}=x^{i, t}+r_{i} \times f l \times\left(m^{j, t}-x^{i, t}\right)$

where $r_{\mathrm{i}}$ is a random variable with a uniform distribution between 0 and 1 , and $f l$ is the flight length. The parameter $f l$ determines the step size of moving towards the solution. The $f l$ values lower than 1 lead to local search or local movement in the search space. Thus, $x^{i, t+1}$ will be between $x^{i, t}$ and $m^{j, t}$ as shown in Fig. 3. On the other hand, the $f l$ value greater than 1 leads to global search. This case means that $x^{i, t+1}$ exceeds $m^{j, t}$ as shown in the same figure.

State 2: if crow $j$ knows that crow $i$ is following it; thus, crow $j$ will deceive crow $i$ and will not go to the hiding place, i.e. will go to any random position.

Both states can be expressed using crow $j$ 's awareness probability (AP) chased at iteration $t$. The parameter $A P$ facilitates a balance between diversification and intensification. Small values of $A P$ correspond to local search conduction, while large values of $A P$ correspond to global but random search conduction [22-26].

Thus the updated position and memory of crow $i$ are given as follows:

$x^{i, t+1}=\left\{\begin{array}{ll}x^{i, t}+r_{i} \times f l \times\left(m^{j, t}-x^{i, t}\right), & \text { if } r_{j} \geq A P \\ \text { a randomposition } & \text { if } r_{j}<A P\end{array}\right\}$

$m^{i, t+1}= \begin{cases}x^{i, t+1}, & \text { if } f\left(x^{i, t+1}\right) \text { is better than } f\left(x^{i, t}\right) \\ m^{i, t} & \text { Otherwise }\end{cases}$

where $f($.$) denotes the value of the objective function.$ 


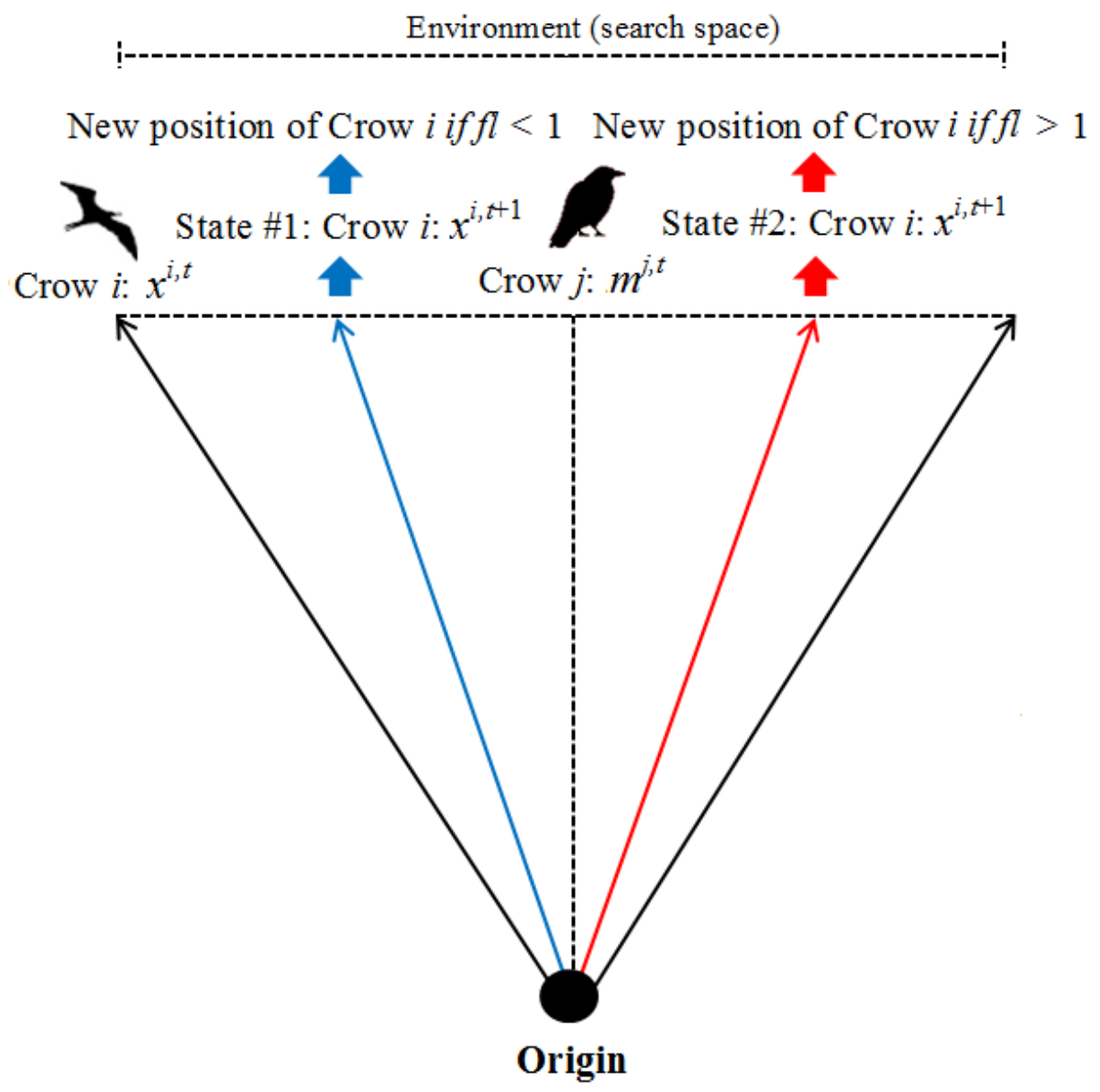

Fig. 3. Effect of $f l$ on the position update

The first step is initialization of the position and memory of the crows after adjusting $N, t_{\max }, f l$ and $A P$ values. Then, the positions of the crows will be updated using Eq. (33), while checking the feasibility of the positions and evaluating the objective function in order to update memory of the crows using Eq. (34). Further, the steps will be repeated until $t_{\max }$ is achieved. Hence, the best solution of the memories will be determined as the optimal solution with the algorithm. Fig. 4 shows the flowchart of the CSA.

Based on the procedure mentioned above, the CSA is implemented by adjusting two parameters (fl and AP). However, the PSO algorithm requires adjusting of four parameters as the maximum value of the velocity, inertia weight, individual and social learning factors, and the GA has six adjustable parameters as the selection method, crossover method, crossover probability, mutation method, mutation probability and replacement method [22]. Besides, it is well known that the success of these metaheuristic techniques depends on the proper adjusting of these parameters. Thus, one can see that the CSA is a much practical method when compared to these techniques. 


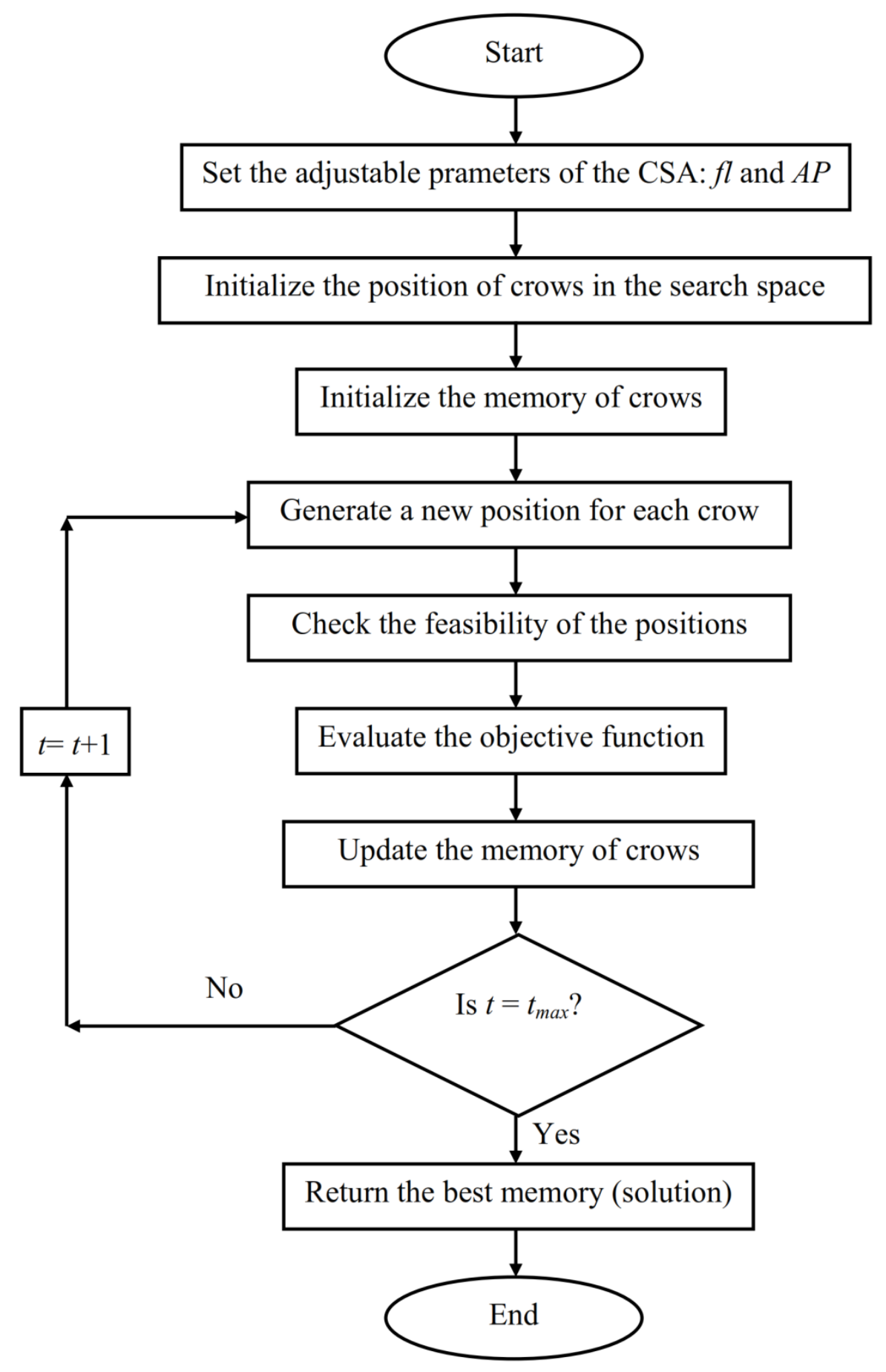

Fig. 4. Flowchart of the CSA

\section{Formulation of the optimization problem}

In this work, the CSA has been implemented to find the optimal design of resonance-free thirdorder shunt passive filters based on minimization of the total filtering costs, while maintaining the desired performance levels.

The case under study, objective function, search space, design scenarios, and constraints are given below. 


\subsection{Case study}

For the system shown in Fig. 2, the numerical data of the equivalent impedance of the system and loads are taken from an example in IEEE Std. 519 [35]. The utility is represented by 80 MVA shortcircuit power, and $4.16 \mathrm{kV}$ line voltage, with $X_{S 1} / R_{S 1}=10$ at the fundamental frequency $(60 \mathrm{~Hz})$. The linear load impedance is given as $Z_{L 1}=1.7421+j 1.696$ at the fundamental frequency. The nonlinear (multiple-pulse DC drives) loads are represented by their equivalent harmonic current source model [36]. Table 1 presents the harmonic spectra of the background voltage and the nonlinear currents as percentages of their fundamental values.

Table 1

Harmonic spectra of the voltage and current sources

\begin{tabular}{ccccccccc}
\hline \hline$N$ & 5 & 7 & 11 & 13 & 17 & 19 & 23 & 25 \\
\hline$E_{S n}(\%)$ & 2.0 & 1.5 & 0.9 & 0.7 & 0.4 & 0.2 & 0.15 & 0.1 \\
$I_{N L}(\%)$ & 2.6 & 1.6 & 3.5 & 2.9 & 0.2 & 0.1 & 0.9 & 0.8 \\
\hline \hline
\end{tabular}

\subsection{Objective function $(\mathrm{OF})$}

Minimization of the total filter cost (FC) is the objective function. It is expressed as a function of the design variables $X_{C 1}, h, R$, and $X_{C 2}$, as follows:

$$
\mathrm{OF}=\text { Minimize } F C=f\left(X_{C 1}, h, R, X_{C 2}\right)
$$

Recalling Eqs. (23), (24), one can express the OF as the minimization of two sub-objectives; the first is the investment cost (IC) which reflects the filter size, and the second is the operating cost (OC) which reflects the damping loss. This is because both size and damping loss are the primary interests in the design of the damped filters.

\subsection{Search space}

The search space is expressed by the lower and upper boundaries of each variable. Regarding $X_{C 1}$, its lower and upper limits are calculated based on the values of reactive power needed to improve the $P F$ within an acceptable range, i.e., (PF> 0.92 lagging). Regarding $h$, its range depends on the pulse number of the drives used; however, because of the background voltage distortion which may amplify the non-filtered non-characteristic harmonic components; the bounds of $h$ is selected as 2 and 11. $R$ should be maintained above its minimum value given in Eq. (11); hence, recalling Eq. (12), the range of $X_{C 2}$ is calculated with respect to the ranges of the other parameters.

\subsection{Design scenarios}

The two possible design scenarios of the $3^{\text {rd }}$ order damped filter are considered. In the first scenario $\left(\mathrm{S}_{1}\right)$, all the design variables vary within their defined search space. In the second scenario $\left(\mathrm{S}_{2}\right)$, an equality constraint of equal capacitors condition is added, i.e. $C_{2}=C_{1}$. Also, the minimum fundamental loss condition is used, this means $R$ is calculated from its minimum value expression given 
in Eq. (11) that corresponds to the case of equal capacitors.

\subsection{Constraints}

The objective function is subjected to the following constraints:

$0.92 \leq P F\left(X_{C 1}, h, R\right.$, and $\left.X_{C 2}\right) \leq 1.00$,

$\operatorname{THDV}\left(X_{C 1}, h, R\right.$, and $\left.X_{C 2}\right) \leq 5.00$,

$\operatorname{THDI}\left(X_{C 1}, h, R\right.$, and $\left.X_{C 2}\right) \leq 5.00$,

$H D I_{n}\left(X_{C 1}, h, R\right.$, and $\left.X_{C 2}\right) \leq H D I_{\text {std }}$,

$H D V_{n}\left(X_{C 1}, h, R\right.$, and $\left.X_{C 2}\right) \leq H D V_{s t d}$, and

$H V A R_{\text {worst }} \leq 1.1$ for all non-characteristic harmonic orders.

where $H D V_{n}$ and $H D I_{n}$ are the individual $n$th harmonic distortion for voltage and current, respectively. $H D I_{s t d}$ is the standard $H D I_{n}$ limit reported in IEEE 519-2014 which depends on both the short-circuit level and harmonic order. Also, $H D V_{\text {std }}$ is the standard $H D V_{n}$ limit reported in IEEE 519-2014 which depends on the voltage level.

In addition, IEEE Standard 18-2012 limits expressed in Eqs. (19)-(22), are taken into account as nonlinear constraints. Moreover, under the worst case of parameter variations due to temperature rise or manufacturing tolerances, $H V A R_{\text {worst }}$ increases by $10 \%$ [16]; consequently, $H V A R_{\text {ref }}$ was set to 1.1 in the base designs to allow a safe margin of parameter variations.

\subsection{C-type filters}

Fig. 1(d) shows the other scheme of the $3^{\text {rd }}$ order HPFs, which is known as the $C$-type filter. It will be compared with the two design scenarios of the first configuration of the $3^{\text {rd }}$ order HPFs to supplement the comparison.

In addition to the design equation of $C_{1}$ given in Eq. (5); the other design equations of $L, C_{2}$ and $R$ can be summarized as given below [16].

$$
\begin{aligned}
& L=\frac{1}{\omega_{1}^{2} C_{2}} \\
& \left(\frac{h^{2}-1}{h^{2}}\right) C_{1} \leq C_{2}<\left(h^{2}-1\right) C_{1} \\
& R=\frac{h^{2}-1}{\omega_{1} h \sqrt{\left(h^{2}-1\right) C_{1} C_{2}-C_{2}^{2}}}
\end{aligned}
$$

In brief, Eqs. (36)-(38) are derived based on the following three conditions.

- $L$ and $C_{2}$ resonate at the fundamental frequency to minimize the fundamental loss.

- At the tuning frequency $(h)$, the filter reactance equals zero.

- Above the tuning frequency, the filter reactance is inductive.

Hence, the OF given in Eq. (35) can be reformulated for the $C$-type filter. 


\section{Results and discussion}

Table 2 shows the optimal circuit parameters and the fitness values of the unequal capacitors, equal capacitors, and $C$-type $3^{\text {rd }}$ order DFs, respectively, obtained using the proposed CSA. The parameter specifications used for controlling the CSA as $t_{\max }$, flock size, $f l$, and $A P$ have been set to 500, 20, 2, and 0.1, respectively. Furthermore, to investigate the validity and performance of the CSA for the studied optimization problem; the obtained filter parameters, achieved fitness values, and average solution time of the CSA and two widely used optimization techniques as genetic algorithm (GA) and particle swarm optimization method (PSO), are presented in the same table. In GA, tournament selection, uniform mutation and convex crossover (with the coefficients of 0.25 and 0.75 ), are used. Crossover and mutation probabilities are set to 0.9 and 0.005 , respectively. In PSO, the learning factors (individual and social) are set to 2. In addition, the velocity is controlled, and the inertia weight decreases linearly from 0.9 to 0.4 during iterations. The population size is set to 20 and the maximum number of iterations is set to 500 in the three algorithms. Besides, 10 independent runs have been executed. It can be pointed out from the comprehensive evaluation of the CSA, GA and PSO that CSA and PSO give very close results to each other and they have better sensitivity than GA. It should also be mentioned that CSA consumes less computational time than the other two algorithms over the same number of fitness evaluations.

Table 2

Optimal circuit parameters of the proposed filters using the CSA, GA, and PSO in terms of sizes of filters, fitness values, and the average running time over 10 independent runs

\begin{tabular}{|c|c|c|c|c|c|c|c|c|c|}
\hline Algorithm & & $\overline{\mathrm{CSA}}$ & & & $\overline{\mathrm{GA}}$ & & & $\begin{array}{l}\text { PSO } \\
\end{array}$ & \\
\hline \multirow[t]{2}{*}{ Parameters } & \multicolumn{2}{|c|}{$\begin{array}{c}3^{\text {rd }} \text { order } \\
\text { damped filter } \\
\text { scenarios }\end{array}$} & \multirow[t]{2}{*}{$C$-type } & \multicolumn{2}{|c|}{$\begin{array}{c}3^{\text {rd }} \text { order } \\
\text { damped filter } \\
\text { scenarios }\end{array}$} & \multirow[t]{2}{*}{$C$-type } & \multicolumn{2}{|c|}{$\begin{array}{c}3^{\text {rd }} \text { order } \\
\text { damped filter } \\
\text { scenarios }\end{array}$} & \multirow[t]{2}{*}{$C$-type } \\
\hline & $S_{1}$ & $S_{2}$ & & $S_{1}$ & $S_{2}$ & & $S_{1}$ & $S_{2}$ & \\
\hline$C_{1}(\mu \mathrm{F})$ & 489.03 & 483.42 & 654.51 & 530.46 & 483.42 & 651.47 & 492.67 & 483.42 & 653.11 \\
\hline$C_{2}(\mu \mathrm{F})$ & 465.71 & 483.42 & 7095.3 & 415.75 & 483.42 & 6900.00 & 457.79 & 483.42 & 7028.10 \\
\hline$R(\Omega)$ & 1.62 & 1.63 & 1.75 & 1.55 & 1.63 & 1.74 & 1.61 & 1.63 & 1.75 \\
\hline$L(\mathrm{mH})$ & 0.63 & 0.64 & 0.99 & 0.56 & 0.64 & 1.00 & 0.62 & 0.64 & 1.00 \\
\hline$h$ (p.u.) & 4.80 & 4.76 & 4.64 & 4.85 & 4.76 & 4.68 & 4.81 & 4.76 & 4.64 \\
\hline Fitness value & 10.34 & 10.36 & 12.71 & 10.62 & 10.36 & 12.73 & 10.34 & 10.36 & 12.72 \\
\hline $\begin{array}{l}\text { Average } \\
\text { time (s) }\end{array}$ & 11.43 & 11.21 & 11.52 & 21.52 & 21.33 & 21.55 & 13.89 & 13.69 & 13.89 \\
\hline
\end{tabular}

Table 3 shows the impact of the designed filters using the CSA on the system performance. 
Besides, the uncompensated system results are included for comparison purpose. By using the $S_{1}, S_{2}$ and $C$-type filters, respectively, it can be noticed that $P F$ is improved from $71.36 \%$ to $95.19 \%, 95.00 \%$ and $98.99 \%, T P_{L}$ is decreased from $18.57 \mathrm{~kW}$ to $11.35 \mathrm{~kW}, 11.39 \mathrm{~kW}$ and $10.73 \mathrm{~kW}$, and $\eta_{T}$ is increased from $98.76 \%$ to $99.30 \%, 99.30 \%$ and $99.35 \%$, respectively. Furthermore, all three filters provide almost the same THDI and THDV values around $5.00 \%$ and $3.00 \%$, respectively. Lastly, with the employement of $S_{1}, S_{2}$ and $C$-type filters, $I_{\mathrm{S}}$ is decreased from 923.75 A to $722.81 \mathrm{~A}, 723.99 \mathrm{~A}$, and $702.76 \mathrm{~A}$, and $V_{\mathrm{L}}$ is increased from $2.25 \mathrm{kV}$ to $2.33 \mathrm{kV}, 2.33 \mathrm{kV}$ and $2.36 \mathrm{kV}$, respectively. This means that for the effective utilization of the lines, $C$-type filter achieves better performance than other two filters, and that all the three filters attain almost the same voltage regulation level.

Table 3

Impact of the designed filters on the system performance

\begin{tabular}{|c|c|c|c|c|}
\hline \multirow{2}{*}{ Parameters } & \multirow{2}{*}{ No filter } & \multicolumn{2}{|c|}{$3^{\text {rd }}$ order damped filter scenarios } & \multirow{2}{*}{$C$-type } \\
\hline & & $S_{1}$ & $S_{2}$ & \\
\hline$P F(\%)$ & 71.36 & 95.19 & 95.00 & 98.99 \\
\hline$T P_{L}(\mathrm{~kW})$ & 18.57 & 11.35 & 11.39 & 10.73 \\
\hline$\eta_{T}(\%)$ & 98.76 & 99.30 & 99.30 & 99.35 \\
\hline$I_{S}(\mathrm{~A})$ & 923.75 & 722.81 & 723.99 & 702.76 \\
\hline THDI (\%) & 5.13 & 5.00 & 5.00 & 5.00 \\
\hline$V_{L}(\mathrm{kV})$ & 2.25 & 2.33 & 2.33 & 2.36 \\
\hline$T H D V(\%)$ & 6.34 & 3.33 & 3.37 & 3.17 \\
\hline
\end{tabular}

Seeking validation of the frequency-domain results of the proposed filter designs, their performance, with the optimal circuit parameters presented in Table 2, is simulated in the time domain via MATLAB\Simulink. The current and voltage quantities as $I_{S}, V_{L}, T H D I$ and $T H D V$ obtained via MATLAB $\backslash$ Simulink are given in Table 4. One can notice from Tables 3 and 4 that the results of frequency and time domain simulations are in close agreement.

Table 4

Time-domain simulation results obtained in MATLAB\Simulink environment

\begin{tabular}{lccc}
\hline Scenarios & $S_{1}$ & $S_{2}$ & $C$-type \\
\hline$I_{S}(\mathrm{~A})$ & 721.99 & 723.10 & 702.00 \\
$V_{L}(\mathrm{kV})$ & 2.33 & 2.33 & 2.36 \\
$T H D I(\%)$ & 5.04 & 5.04 & 5.04 \\
$T H D V(\%)$ & 3.34 & 3.39 & 3.18 \\
\hline \hline
\end{tabular}

Fig. 5 shows the improvement of the fitness value versus the iteration number during the search 
algorithm: convergence rate, for the three filter designs, respectively. It can be noticed that the CSA algorithm finds a good region of the search space at the first iterations and converges quickly to the optimal solution of the formulated optimization problem after 100, 50, and 50 iterations for the $S_{1}, S_{2}$, and $C$-type filters, respectively. For these iterations, the average solution time is measured as 11.43 , 11.21 and $11.52 \mathrm{~s}$, respectively.

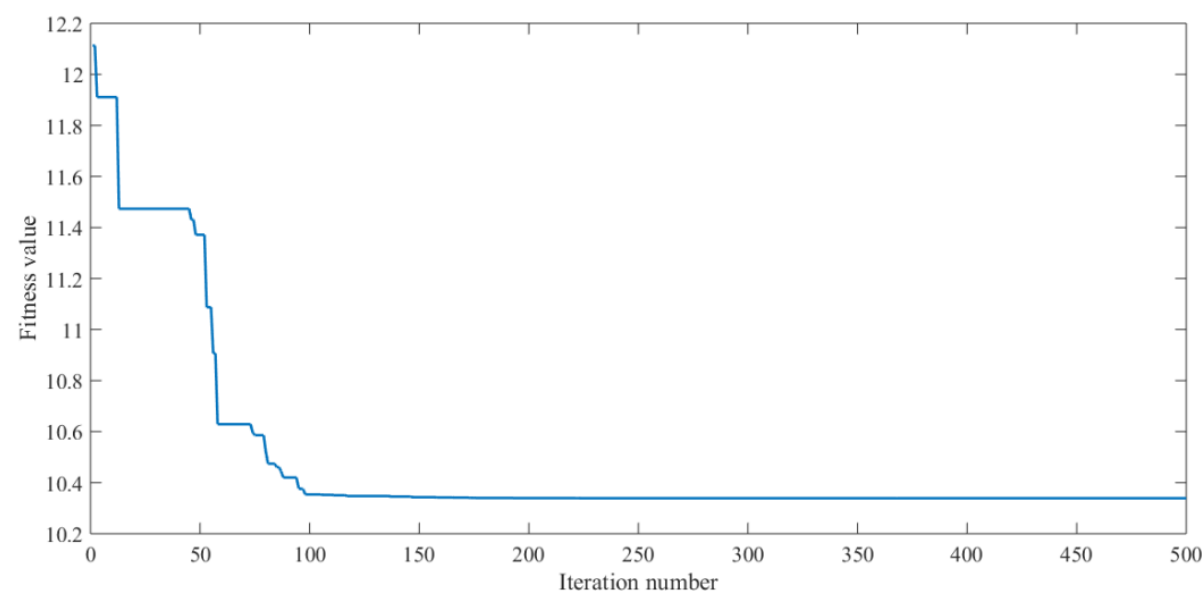

(a) Different capacitors-based scenario $\left(\mathrm{S}_{1}\right)$

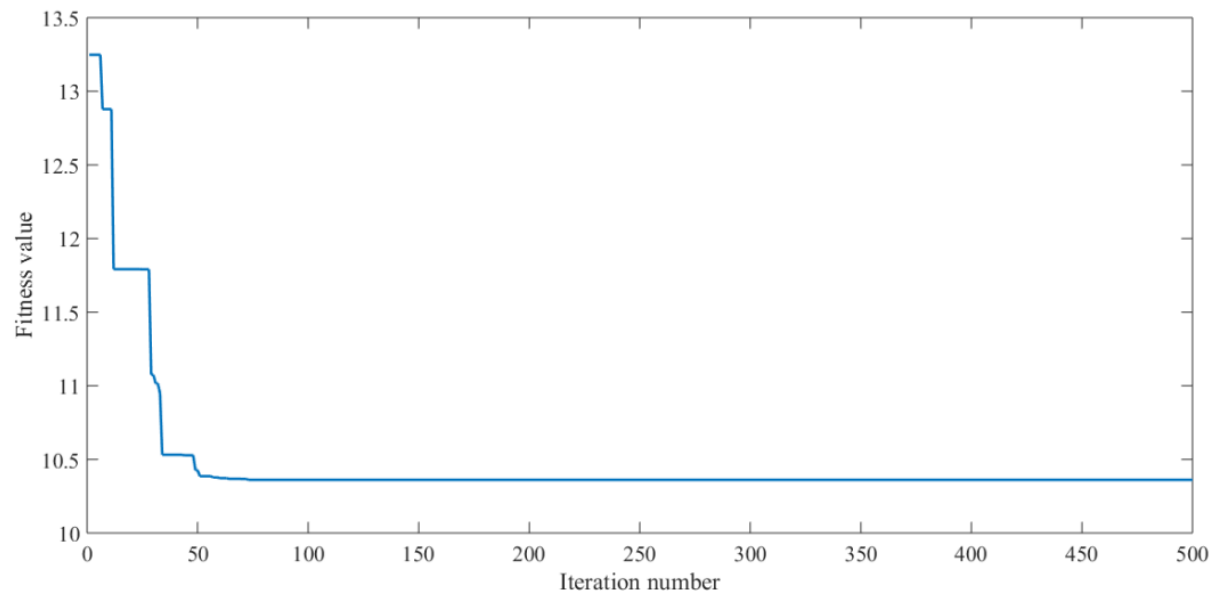

(b) Equal capacitors-based scenario $\left(\mathrm{S}_{2}\right)$

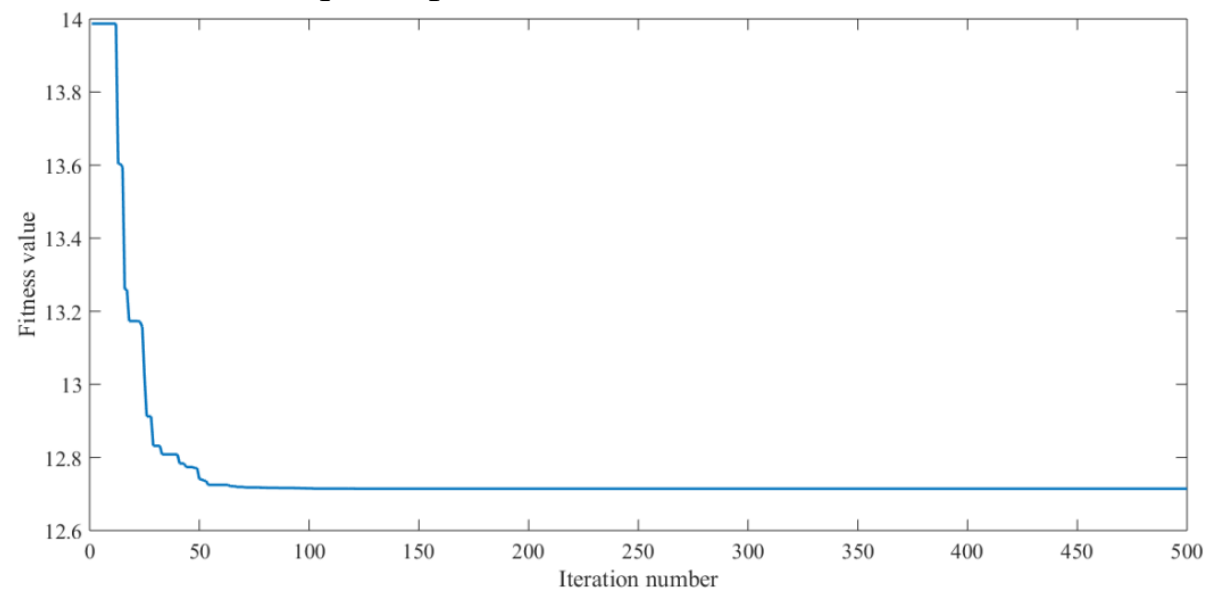

(c) $C$-type filter

Fig. 5. The convergence rate of the CSA for the three considered filters 
Since it is important to show how the flight length and awareness probability affect the optimal solution obtained using the CSA, different cases are studied and presented in Table 5. Four independent values are assumed for $f l$ such as $0.1,1,2$, and 4 , in addition to considering three independent values for $A P$ such as $0.1,0.1$, and 0.8 . It is assumed that all other parameters are kept constant. As mentioned earlier, small $f l$ values are likely to lead to locally optimal solutions, while large enough values of $f l$ can give rise to globally optimal solutions. Additionally, it is clear that better solutions can be obtained with small values of $A P$. Furthermore, it is noticed that near-optimal solutions can be obtained if the parameter specifications used for controlling the CSA are not well adjusted. Finally, the sensitivity analysis results given in Table 5 for the three considered filters ensure that the base cases, given in bold type, achieve better optimal solutions.

Table 5

Effects of changing the flight length and awareness probability on the optimal solutions $3^{\text {rd }}$ order damped filter scenarios

\begin{tabular}{l|lllllllll}
\cline { 2 - 9 } & \multicolumn{3}{c}{$S_{1}$} & \multicolumn{3}{c}{$S_{2}$} & \multicolumn{3}{c}{$C$-type } \\
\cline { 2 - 10 } & $\boldsymbol{A P = \mathbf { 0 . 1 }}$ & $A P=0.4$ & $A P=0.8$ & $\boldsymbol{A P}=\mathbf{0 . 1}$ & $A P=0.4$ & $A P=0.8$ & $\boldsymbol{A P}=\mathbf{0 . 1}$ & $A P=0.4$ & $A P=0.8$ \\
\hline$f l=0.1$ & 10.69383 & 11.12472 & 10.82259 & 10.46302 & 10.58246 & 10.45252 & 13.61404 & 13.46465 & 13.22121 \\
$f l=1$ & 10.40953 & 10.51155 & 10.48544 & 10.39483 & 10.37200 & 10.43938 & 13.84538 & 13.20743 & 12.96939 \\
$f l=\mathbf{2}$ & $\mathbf{1 0 . 3 3 9 0 9}$ & 10.34260 & 10.45610 & $\mathbf{1 0 . 3 6 0 7 7}$ & 10.36136 & 10.39637 & $\mathbf{1 2 . 7 1 4 2 5}$ & 12.71432 & 12.73549 \\
$f l=4$ & 10.37351 & 10.48342 & 10.79784 & 10.36283 & 10.36536 & 10.38463 & 12.71445 & 12.72953 & 12.75887 \\
\hline \hline
\end{tabular}

Fig. 6 shows the impedance-frequency response $\left(\mathrm{R}_{\mathrm{F}}, \mathrm{X}_{\mathrm{F}}, \mathrm{Z}_{\mathrm{F}}\right)$ of the three filters, respectively. As obvious, $S_{1}$ and $S_{2}$ have very close impedance-frequency characteristics. In addition, it is evident that the $C$-type filter has better damping characteristics as reflected by its large equivalent resistance that can damp the amplification of harmonic voltages, followed by the equal capacitors $3^{\text {rd }}$ order filter design $\left(\mathrm{S}_{2}\right)$, followed by the unequal capacitors $3^{\text {rd }}$ order filter design $\left(\mathrm{S}_{1}\right)$.

Fig. 7 shows the harmonic spectra of the voltage and current, calculated at the PCC, respectively. All the individual harmonic components are well below the standard limits.

Although the performance of the designed filters is comparable, $S_{1}$ presents a better mitigation for the low order harmonic voltage components such as the $5^{\text {th }}$ and the $7^{\text {th }}$ harmonic orders, while the $C$ type presents a better mitigation for the higher order harmonic voltage components. Regarding the mitigated individual harmonic current components, performance of the three designed filters is almost the same. 

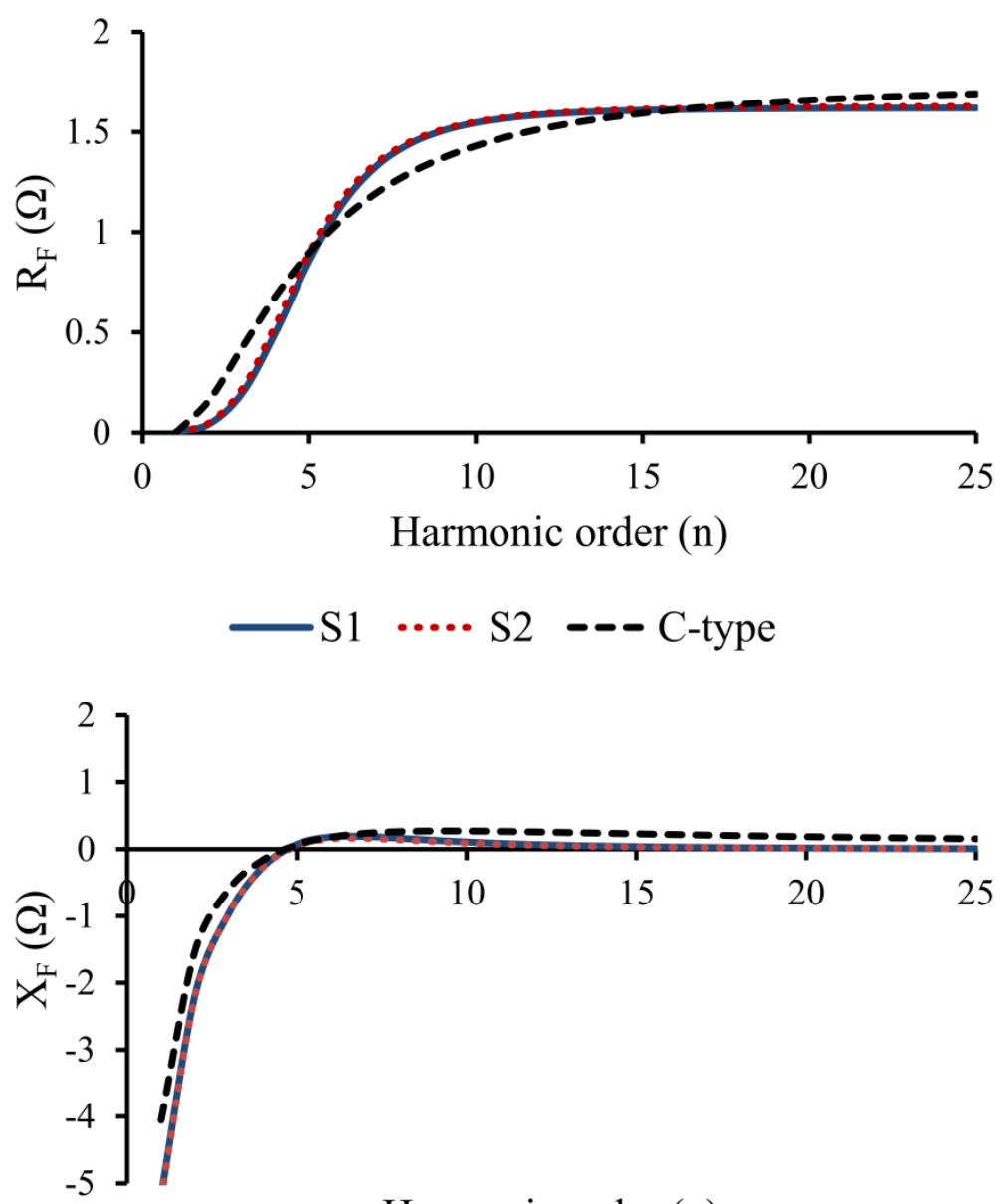

Harmonic order (n)

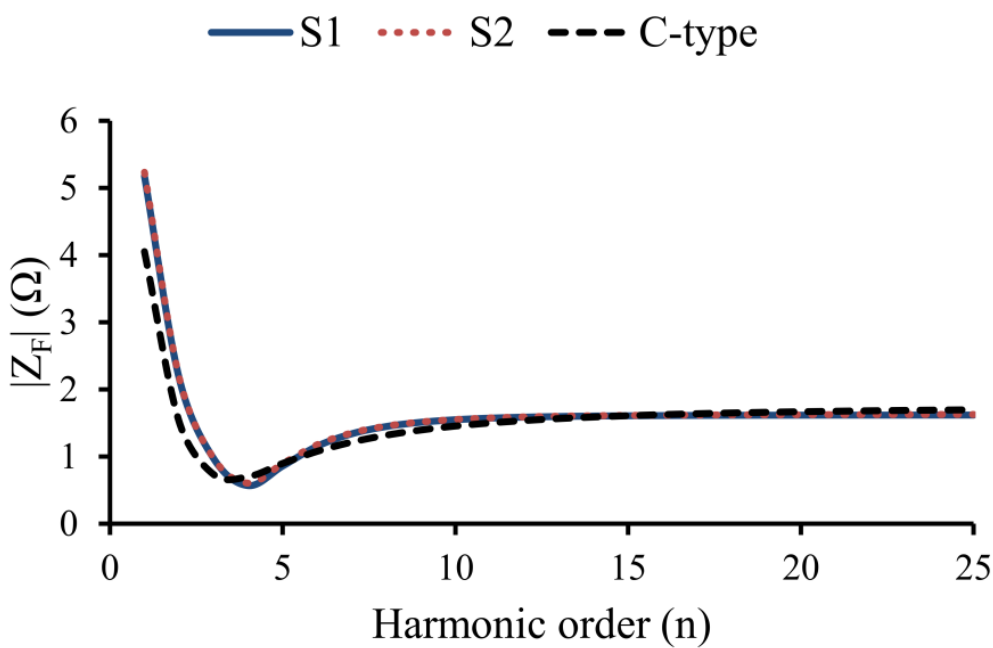

$\longrightarrow$ S1 $\ldots . . S$ S2 --- C-type

Fig. 6. Impedance-frequency response of the considered filters 


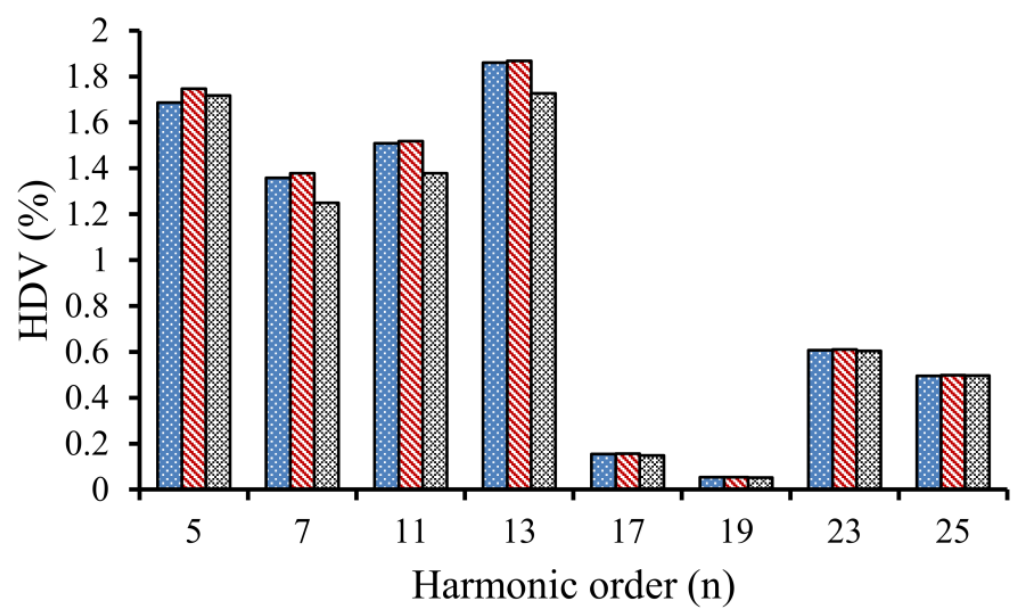

$\mathbb{S} 1 \mathbb{S} 2$ 圆 C-type

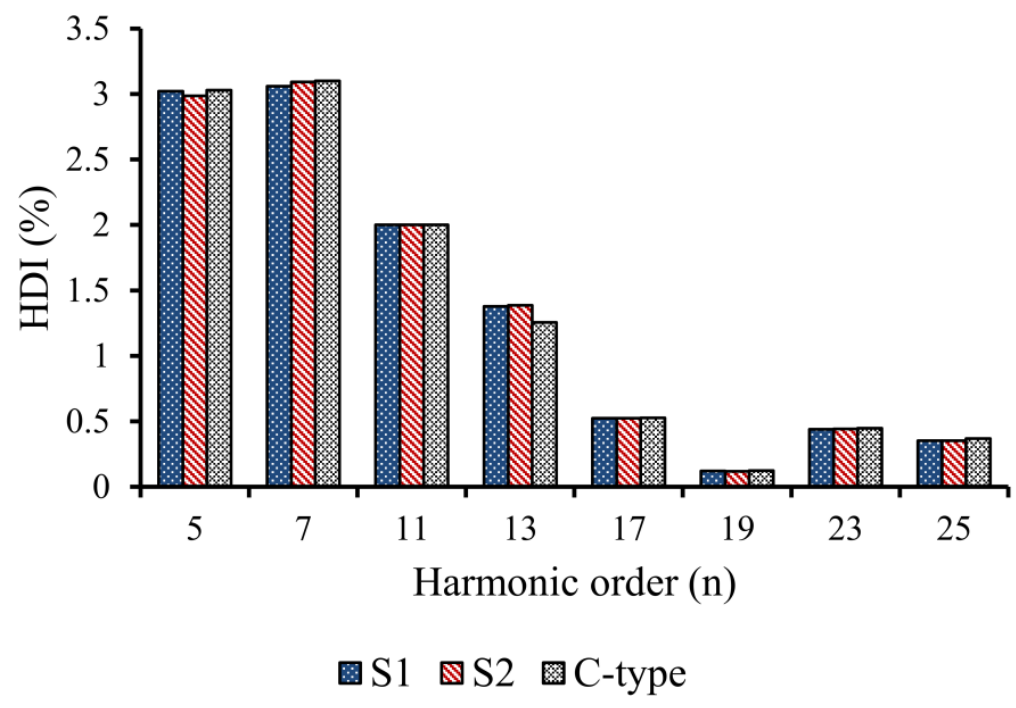

Fig. 7. Resultant voltage and current individual harmonic distortions

Fig. 8 shows the $H M C$ of the designed filters at non-characteristic and characteristic harmonic orders. It is clearly seen that the $C$-type filter has better average $H M C$ compared to the other filter designs.

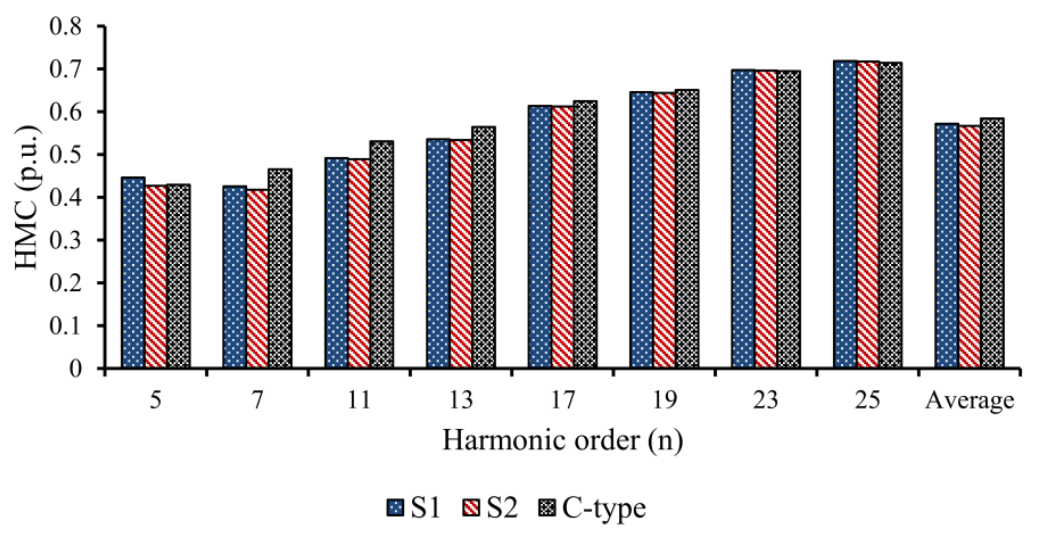

Fig. 8. Harmonic mitigation capabilities of the considered filters 
Regarding the parallel resonance damping capabilities of the filters, Fig. 9 shows the frequency response of the equivalent impedance seen from the load side $\left(\left|Z_{n}\right|\right)$ and the corresponding $F S$ values. Obviously, $C$-type filters guarantee better damping for all the considered frequency range, while the other two scenarios are comparable. On the other hand, for the resonance damping capabilities of the filters under the worst case condition, Fig. 10 shows a comparison of the $H V A R_{\text {worst }}$ values. All the designed filters have a significant capability of damping the series resonance under the worst-case condition and all of them are well below the threshold limit; however, $S_{2}$ has much better performance compared to others, while the $C$-type has the worst one. It should be noted that the $H V A R_{\text {worst }}$ values of the $C$-type filter can be lower, but with a considerable increase in the cost. In general, negligible harmonic voltage amplification may occur with an average $H V A R_{\text {worst }}$ very close to 1 for all the designed filters.
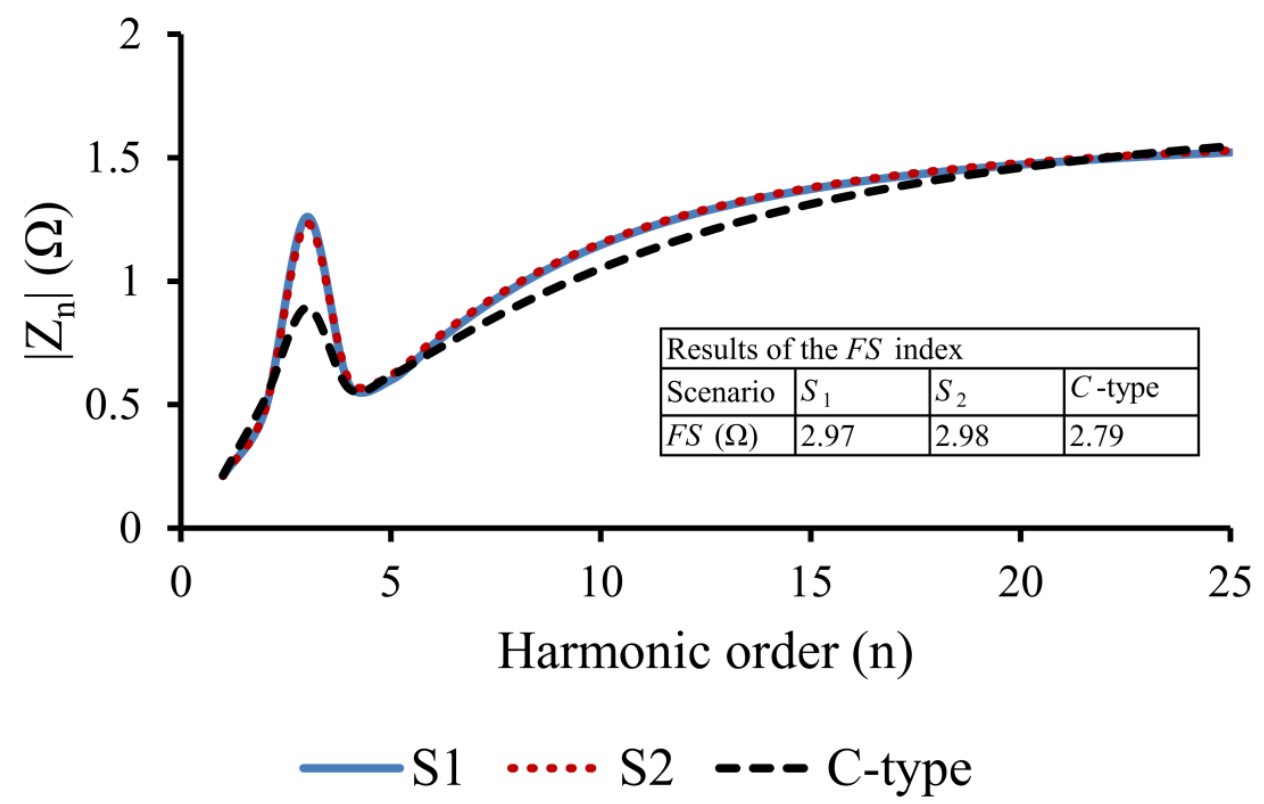

Fig. 9. The frequency response of the equivalent impedance seen from the load side

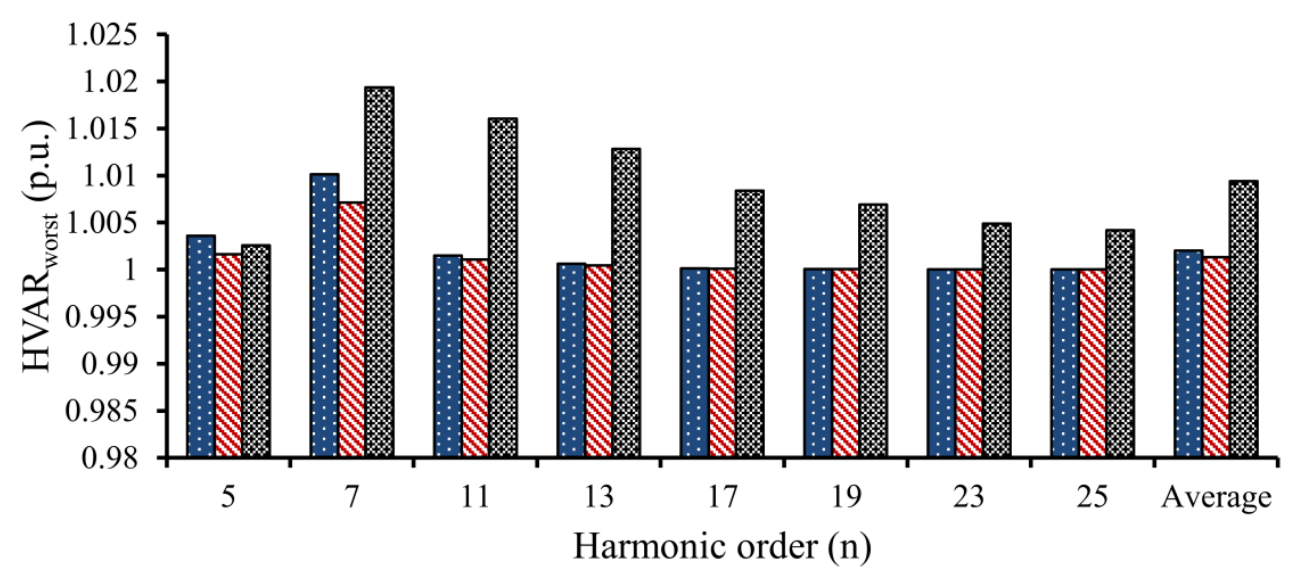

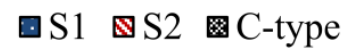

Fig. 10. Comparison of the $H V A R_{\text {worst }}$ values 
Table 6 shows the IEEE Std. 18 limitations for the loading limits of the main capacitors of the proposed filters. All of them are well below the standard limits.

Table 6

Capacitor loading limits

\begin{tabular}{lcccc}
\hline Scenarios & $S_{1}$ & $S_{2}$ & $C$-type & IEEE Std. 18 limitations (\%) \\
\hline$I_{C} / I_{\text {rated }}(\%)$ & 103.58 & 102.90 & 98.89 & 135 \\
$V_{C} / V_{\text {rated }}(\%)$ & 102.83 & 101.90 & 98.34 & 110 \\
$V_{\text {peak }} / V_{\text {rated }}(\%)$ & 105.78 & 105.86 & 101.24 & 120 \\
$Q_{C 1} / Q_{\text {rated }}(\%)$ & 104.73 & 104.85 & 97.25 & 135 \\
\hline \hline
\end{tabular}

Table 7 shows a comprehensive power loss and cost comparison of the proposed filters. It can be seen from the table that fundamental harmonic power losses of $S_{1}, S_{2}$, and $C$-type filters are $0.56 \mathrm{~kW}$, $0.63 \mathrm{~kW}$, and $0.00 \mathrm{~kW}$, respectively. They have non-fundamental harmonic power losses as $4.72 \mathrm{~kW}$, $4.80 \mathrm{~kW}$, and $4.47 \mathrm{~kW}$, respectively. As a result, their total electrical power losses are calculated as $5.28 \mathrm{~kW}, 5.43 \mathrm{~kW}$, and $4.47 \mathrm{~kW}$, respectively. This case shows that the filters with the lowest and highest electrical losses are the $C$-type and $S_{2}$ filters, respectively. Moreover, for $S_{1}, S_{2}$, and $C$-type filters, it can be seen from the investment and operating cost results that the filters with the lowest and highest costs are the $S_{1}$ and $C$-type filters, respectively. This means that the $C$-type filters guarantee effective harmonic mitigation and resonance damping capabilities with low damping losses, but with almost $23 \%$ increase in the total cost.

Table 7

Power losses and cost comparison of the considered filters

\begin{tabular}{lccc}
\hline \multicolumn{1}{c}{ Scenarios } & $S_{1}$ & $S_{2}$ & $C$-type \\
\hline Fundamental harmonic power loss $(\mathrm{kW})$ & 0.56 & 0.63 & 0.00 \\
Non-fundamental harmonic power loss $(\mathrm{kW})$ & 4.72 & 4.80 & 4.47 \\
Total filter power losses $(\mathrm{kW})$ & 5.28 & 5.43 & 4.47 \\
$I C\left(* 10^{4}\right.$ L.E. $)$ & 7.24 & 7.16 & 10.09 \\
$O C\left(* 10^{4}\right.$ L.E. $)$ & 3.10 & 3.19 & 2.63 \\
$F C\left(* 10^{4}\right.$ L.E. $)$ & 10.34 & 10.36 & 12.71 \\
\hline \hline
\end{tabular}

Finally, responses of the total cost characteristics of the three considered filter designs among the allowable ranges of the design variables are examined in order to validate the performance of the proposed filter designs. The results shown in Fig. 11 for the three filter designs validate the effectiveness of the proposed solutions. As obvious, the total costs of all three filter designs are mainly 
affected by their main capacitance $\left(C_{1}\right)$ values, and the filters providing higher capacitive reactive power have a higher total cost. The $S_{1}$ filter with a higher filter resistor value $(R)$ has lower total filter costs (FC) since the increase of $R$ results in lower filter losses and operating costs. The $F C$ of the $S_{1}$ and $S_{2}$ filters are improved by adjusting the tuning harmonic order (h) close to the lowest dominant harmonic order of the system. In addition, for the $C$-type filter, effect of $h$ and $C_{2}$ on the $F C$ is negligible when compared to $C_{1}$.

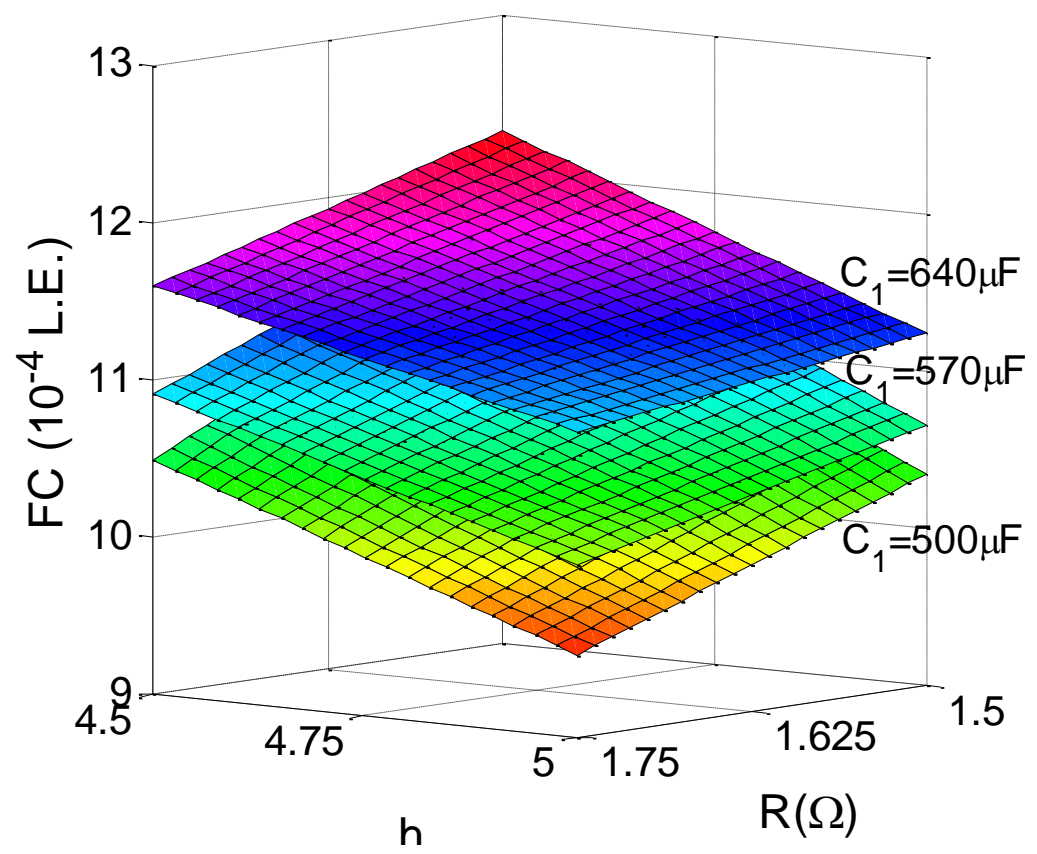

(a) Different capacitors-based scenario $\left(S_{1}\right)$

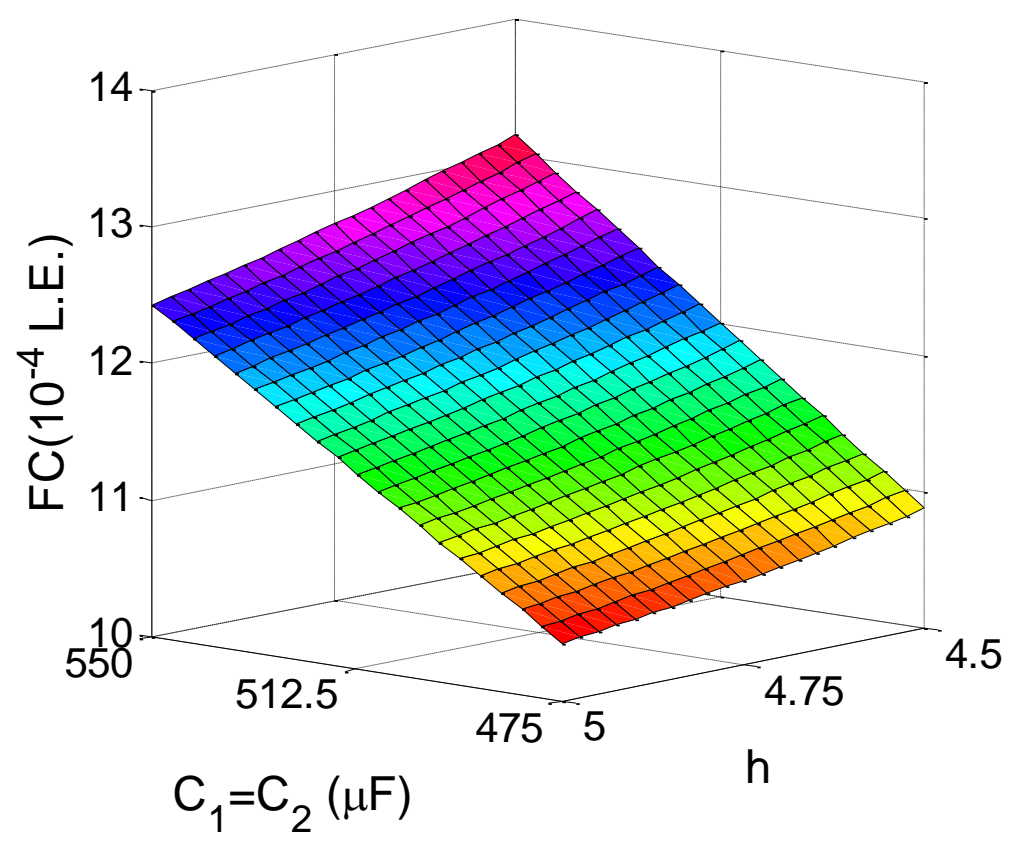

(b) Equal capacitors-based scenario $\left(\mathrm{S}_{2}\right)$ 


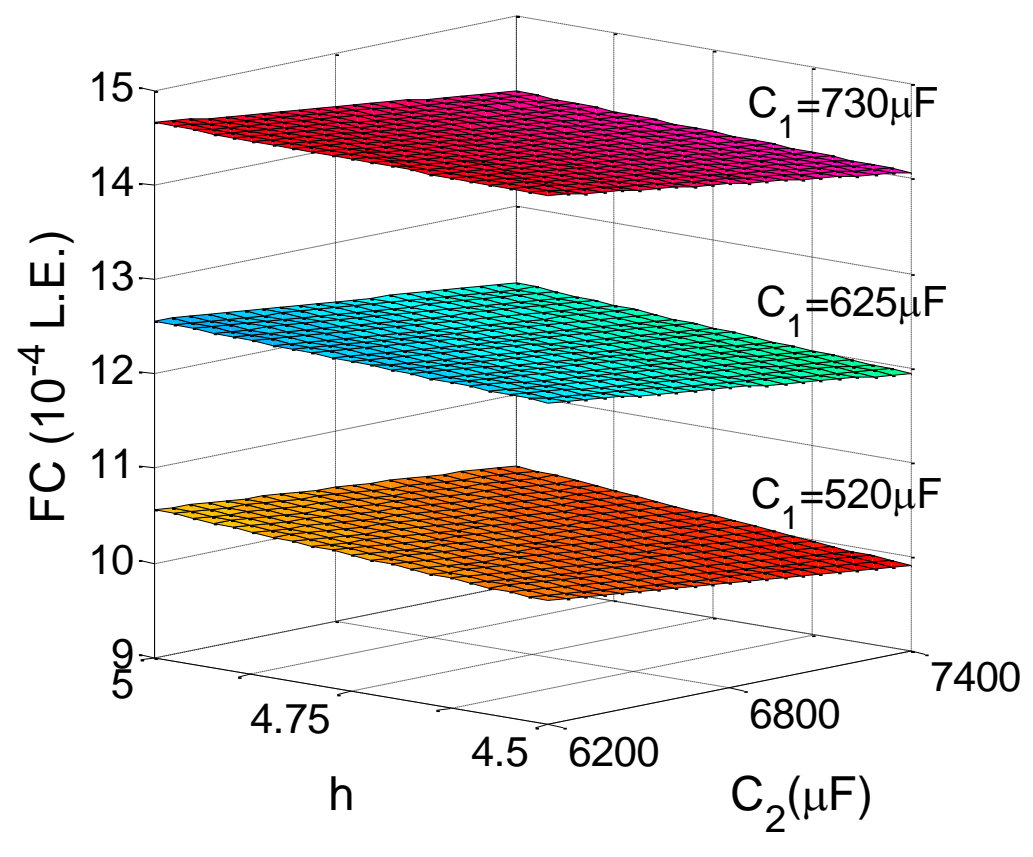

(c) $C$-type filter

Fig. 11. FC variations of the three proposed filter designs

\section{Conclusions}

Harmonic resonance is a significant matter of interest in the application of passive filters. In this regard, practicing resonance-free shunt capacitors that do not depend on the system conditions has become more attractive, particularly for HVDC and transmission systems. In distribution systems, this kind of filters is also of interest because it can be used for randomly varying loads [27]. Generally speaking, the main problem of damped filters is the increased power loss in their damping circuits [37]. Also, their size may relatively increase than conventionally designed filters which have more design freedom [29].

In this paper, for the third-order damped filter with equal and unequal capacitors, the relations among their circuit parameters are expressed by considering their tuning harmonic order, fundamental harmonic loss and required fundamental harmonic reactive power compensation. The features of each scheme have been presented. Besides, the third-order $C$-type filter is considered under the same design scenarios to supplement the comparisons and generalize the findings for all the third-order resonancefree filter schemes.

Crow Search Algorithm (CSA) is used for the optimal filter design to minimize the total filter cost that includes both the investment and operating expenses. CSA is a recent metaheuristic optimization technique which is based on the intelligent behavior of crows. Besides, the CSA is compared to the genetic algorithm (GA), and particle swarm optimization (PSO) techniques and the 
results show the fast convergence capability and the effectiveness of the proposed algorithm in solving the problem of optimal design of third-order resonance-free passive filters in distribution networks.

The results reveal that all the proposed filters guarantee no electrical resonance hazards while maintaining the allowable limits for the various performance indices of the system, load, and filter. Besides, the comparative analysis validates that the $C$-type filter provides higher power factor, system efficiency and transmission loss improvement than the other two filters, and that the proposed filters achieve almost the same voltage and current harmonic mitigation levels. The solution of the cost minimization problem reveals that the $C$-type filter and the third-order high-pass filter with equal capacitors have the worst and best resonance damping capabilities respectively, under the worst case conditions. Additionally, the filters with the lowest and highest cost are found as the third-order filter with unequal capacitors and the $C$-type one, respectively.

Finally, compared to the tuned filters, performance of the damped filters is more durable to the variations that may occur due to frequency deviation, manufacture tolerance, and temperature changes. Also, the conventional third-order filters are less sensitive to the changes compared to $C$-type filters [16]. However, it is possible to reduce the variations related to manufacturing tolerances with measurements during the factory tests or after the commissioning to reduce the variations of the resonances during the system operation [10], but additional costs may be required for specifying closer tolerances on capacitors and reactors of the $C$-type filters [3].

\section{Acknowledgement}

The authors would like to thank the anonymous reviewers for their constructive comments and suggestions. 


\section{References}

[1] Sakar S, Balci ME, Abdel Aleem SHE, Zobaa AF. Increasing PV hosting capacity in distorted distribution systems using passive harmonic filtering. Electr Power Syst Res., 2017; 148:74-86. DOI: 10.1016/j.epsr.2017.03.020.

[2] Rönnberg SK, Bollen MHJ, Amaris H, Chang GW, Gu IYH, Kocewiak ŁH, et al. On waveform distortion in the frequency range of $2 \mathrm{kHz}-150 \mathrm{kHz}$ - Review and research challenges. Electr Power Syst Res., 2017; 150:1-10.

[3] Das JC. Power System Harmonics and Passive Filter Designs, $1^{\text {st }}$ ed. United States of America: Wiley-IEEE Press, May 2015. DOI: 10.1002/9781118887059.

[4] Leite JC, Abril IP, Tostes MEDL, Oliveira RCL De. Multi-objective optimization of passive filters in industrial power systems. Electr Eng, 2016:1-9. DOI:10.1007/s00202-016-0420-3.

[5] Zobaa AF, Abdel Aleem SH. Power Quality in Future Electrical Power Systems, $1^{\text {st }}$ ed. United Kingdom: IET, March 2017. DOI: 10.1049/PBPO092E.

[6] Urbanetz J, Braun P, Rüther R. Power quality analysis of grid-connected solar photovoltaic generators in Brazil. Energy Convers. Manag., 2012, 64: 8-14. DOI: 10.1016/j.enconman.2012.05.008.

[7] Kumar DR, Anuradha K, Saraswathi P, Gokaraju R, Ramamoorty M. New low cost passive filter configuration for mitigating bus voltage distortions in distribution systems. In IEEE International Conference on Building Efficiency and Sustainable Technologies, 2015; 79-84. DOI: 10.1109/ICBEST.2015.7435869.

[8] Zobaa AF, Abdel Aleem SHE. A new approach for harmonic distortion minimization in power systems supplying nonlinear loads. IEEE Trans. on Industrial Informatics, 2014; 10: 1401-1412. DOI: 10.1109/TII.2014.2307196.

[9] Busarello TDC, Pomilio JA, Simoes MG. Passive filter aided by shunt compensators based on the conservative power theory. IEEE Trans. on Industry Applications, 2016; 52: 3340-3347. DOI 10.1109/TIA.2016.2544829.

[10] Pinceti P, Prando D. Sensitivity of parallel harmonic filters to parameters variations. Int J Electr Power Energy Syst, 2015; 68:26-32. DOI: 10.1016/j.ijepes.2014.12.030.

[11] Vedam RS, Sarma MS. Power Quality: VAR Compensation in Power Systems, 1st ed. United States: CRC Press, 2008.

[12] Kececioglu OF, Acikgoz H, Sekkeli M. Advanced configuration of hybrid passive filter for reactive power and harmonic compensation. SpringerPlus 2016; 5: 1228. DOI: 10.1186/s40064016-2917-7.

[13] Peng FZ, Gui-Jia S, Farquharson G. A series LC filter for harmonic compensation of AC drives. In 30th Annual IEEE Power Electronics Specialists Conference, 1999, 213-218. DOI: 10.1109/PESC.1999.789005.

[14] Zobaa AF, Abdel-Aziz MM, Abdel Aleem SHE. Comparison of shunt-passive and seriespassive filters for DC drives loads. Electric Power Components and Systems, 2010; 38: 275-291. DOI: $10.1080 / 15325000903273262$.

[15] Chang Y-P. Optimal harmonic filters design of the Taiwan high speed rail traction system of distributer generation system with specially connected transformers. Int $J$ Electr Power Energy Syst, 2014; 62:80-9. DOI: 10.1016/j.ijepes.2014.02.014.

[16] Xu W, Ding T, Li X, Liang H. Resonance-free shunt capacitors - configurations, design methods and comparative analysis. IEEE Trans. on Power Delivery, 2016; 31: 2287-2295. DOI: 10.1109/TPWRD.2015.2507440. 
[17] Abdel Aleem SHE, Balci ME, Sakar S. Optimal passive filter design for effective utilization of cables and transformers under non-sinusoidal condition. Int J Electr Power Energy Syst, 2015; 71: 344-350. DOI: 10.1016/j.ijepes.2015.02.036.

[18] Xiao Y. The method for designing the third order filter. In 8th International Conference on Harmonics and Quality of Power, ICHQP 1998; 139-142. DOI: 10.1109/ICHQP.1998.759862.

[19] CIGRE WG 14.03, AC harmonic filters and reactive compensation for HVDC with particular reference to non-characteristic harmonics, Tech. Rep. TB-065, Jun. 1990.

[20] Kovernikova LI. Centralized normalization of harmonic voltage by the third-order filters. In International Conference on Renewable Energies and Power Quality, ICREPQ'10, 2010.

[21] Ding T, Xu W, Liang H. Design method for third-order high-pass filter. IEEE Transactions on Power Delivery, 2016; 31: 402-403. DOI: 10.1109/TPWRD.2015.2457831.

[22] Askarzadeh A. A novel metaheuristic method for solving constrained engineering optimization problems: Crow search algorithm. Computers \& Structures, 2016; 169: 1-12. DOI: 10.1016/j.compstruc.2016.03.001.

[23] Abdelaziz AY, Fathy A. A novel approach based on crow search algorithm for optimal selection of conductor size in radial distribution networks. Engineering Science and Technology, an International Journal, April 2017; 20: 391-402. DOI: 10.1016/j.jestch.2017.02.004.

[24] Askarzadeh A. Capacitor placement in distribution systems for power loss reduction and voltage improvement: a new methodology. IET Generation, Transmission \& Distribution, 2016; 10: 3631-8. DOI: 10.1049/iet-gtd.2016.0419.

[25] Coelho L.d S, Richter C, Mariani VC, Askarzadeh A. Modified crow search approach applied to electromagnetic optimization. In 2016 IEEE Conference on Electromagnetic Field Computation (CEFC), Miami, FL, 2016, pp. 1-1. DOI: 10.1109/CEFC.2016.7815927.

[26] Sayed GI, Hassanien AE, Azar AT. Feature selection via a novel chaotic crow search algorithm. Neural Comput \& Applic, 2017; 1-8. DOI:10.1007/s00521-017-2988-6.

[27] Abdel Aleem SHE, Zobaa AF, Aziz MM. Optimal $C$-type passive filter based on minimization of the voltage harmonic distortion for nonlinear loads. IEEE Trans. on Industrial Electronics, 2012; 59: 281-289. DOI: 10.1109/TIE.2011.2141099.

[28] Klempka R. Design of C-type passive filter for ARC furnaces. Metalurgija., 2017; 56: 161-163.

[29] Beres RN, Wang X, Liserre M, Blaabjerg, Bak CL. A review of passive power filters for threephase grid-connected voltage-source converters. IEEE Journal of Emerging and Selected Topics in Power Electronics, 2016; 4: 54-69. DOI: 10.1109/JESTPE.2015.2507203.

[30] IEEE standard for shunt power capacitors, IEEE Standard 18-2012, 2012.

[31] Independent pricing and regulatory tribunal of new south wales, method guide power factor correction energy savings formula: deemed energy savings method. Energy savings scheme, Jan. 2015. [Online]. Available: http://www.ess.nsw.gov.au/files/353708d1-ab17-4aa4-96a5a41b0103d03f/Method_Guide_-_Power_Factor_Correction_-_V20.pdf [Accessed 10/5/2017].

[32] Arrillaga J, Watson NR. Power System Harmonics, 2nd ed., United States: John Wiley \& Sons, Nov. 2003.

[33] Nassif AB, Xu W, Freitas W. An investigation on the selection of filter topologies for passive filter applications. IEEE Trans. Power Del., 2009; 24: 1710-1718. DOI: 10.1109/TPWRD.2009.2016824.

[34] Abdel Aleem SHE, Zobaa AF. Optimal C-type filters for harmonics mitigation and resonance damping in industrial distribution systems. Electr Eng, 2017; 99: 107-118. DOI: 10.1007/s00202016-0406-1. 
[35] IEEE Recommended Practices and Requirements for Harmonic Control in Electrical Power Systems, IEEE 519, 2012.

[36] Li X, Xu W, Ding T. Damped high passive filter - a new filtering scheme for multipulse rectifier systems. IEEE Trans. on Power Delivery, 2017; 32: 117-124. DOI: 10.1109/TPWRD.2016.2541621.

[37] Kalair A, Abas N, Kalair AR, Saleem Z, Khan N. Review of harmonic analysis, modeling and mitigation techniques. Renew Sustain Energy Rev., 2017;78:1152-87. DOI:10.1016/j.rser.2017.04.121. 